\title{
¿CÓMO SE NOMBRA DISCRECIONALMENTE EL PODER JUDICIAL? EL CONSEJO GENERAL DEL PODER JUDICIAL Y LA JUDICIAL APPOINTMENT COMMISSION EN EL REINO UNIDO.
}

ROSA Ma ${ }^{a}$. FERNÁNDEZ RIVEIRA 
I.- INTRODUCCIÓN II.- LOS PROCESOS DE NOMBRAMIENTOS REGLADOS Y "DISCRECIONALES" EN ESPAÑA; a) Las competencias del Consejo General del Poder Judicial en materia de nombramientos; b) La evolución de la Jurisprudencia de los "nombramientos discrecionales". III.- EL SIGNIFICADO DE LOS PROCEDIMIENTOS DE SELECCIÓN DE LA JUDICATURA PARA LA INDEPENDENCIA JUDICIAL. IV.- LOS NOMBRAMIENTOS DE LA JUDICATURA BRITÁNICA DESPUÉS DE LA CONSTITUTIONAL REFORM ACT DE 2005. V.- CONCLUSIONES: A MODO DE SINERGIAS, PREOCUPACIONES Y REFLEXIONES TRAS LA COMPARATIVA. 


\title{
¿CÓMO SE NOMBRA DISCRECIONALMENTE EL PODER JUDICIAL? EL CONSEJO GENERAL DEL PODER JUDICIAL Y LA JUDICIAL APPOINTMENT COMMISSION EN EL REINO UNIDO
}

\author{
ROSA M ${ }^{\mathrm{a}}$. FERNÁNDEZ RIVEIRA ${ }^{1}$ \\ Profesora Titular de Derecho Constitucional \\ UNIVERSIDAD COMPLUTENSE DE MADRID
}

"It there is a moral it is that, while what matters to the wider world is what judges do, what matters to judges is why they do it”2, STEPHEN SEDLEY, Lions under the Throne. Essays on the History of English Public Law. Cambridge University Press 2015

\section{INTRODUCCIÓN ${ }^{3}$}

Nadie duda que necesitamos un Poder Judicial independiente como esencia de nuestra democracia. El poder judicial independiente existe y es. PABLO LUCAS

\footnotetext{
1 Departamento de Derecho Constitucional. Facultad de Derecho. Universidad Complutense de Madrid. Ciudad Universitaria. 28040 Madrid. Email: ferrosa@ucm.es

2 La idea expresa que, si hay una moraleja en esto es que, mientras al mundo le preocupa lo que hacen los jueces, a los jueces lo que verdaderamente les preocupa es porqué lo hacen.

3 Este trabajo se cierra antes de las últimas reformas sobre la Ley Orgánica del Poder Judicial, leyes 4/2018 y 5/2018 de 28 de diciembre, pues se entrega apenas publicadas éstas. En ellas se introducen ciertos aspectos de interés sobre nombramientos discrecionales que abundan en la línea de: a) reforzar el mérito, capacidad, idoneidad y especialización; b) se sigue apostando por el modelo de Consejo fuerte con fuertes competencias en la figura de su Presidente; c) se hace un guiño favorable a la presencia pari-
} 
MURILLO defiende que los jueces españoles son independientes en el ejercicio de la potestad jurisdiccional, frente a los otros poderes públicos y frente a las partes..."4

¿Qué es un Poder Judicial independiente? ${ }^{5}$

Encontraremos tantas respuestas como modelos judiciales, como visiones de los propios Jueces y Magistrados, como experiencias de ciudadanos ante sus instituciones judiciales. La independencia judicial se construye, es un logro político.

No hablamos de un concepto teórico puro, aséptico, por encima de cualquier realidad, como imperativo categórico. Nos referimos a la independencia judicial que surge como consecuencia de un determinado escenario de separación de poderes, de un concreto proceso de selección de Jueces, dentro de un modelo institucional concreto, con Consejo o sin él. A la independencia judicial fruto de unas políticas concretas en materia salarial de nuestros jueces, con unas normas que operan la promoción de la carrera judicial, con unas cifras determinadas de hombres y mujeres, con una edad de jubilación concreta, con mejores o peores relaciones con los medios de comunicación. Una independencia judicial que maneja un determinado concepto de mérito y/o "reconocida competencia". A una "independencia judicial" que es libre de creer o no en la responsabilidad de sus jueces y magistrados y que decide cómo y hasta dónde se debe articular esa responsabilidad.

La independencia judicial no es un concepto estático, no responde a unas premisas fijas que puedan, permanentemente, garantizarla. Se construye, se reajusta, se diseña y rediseña.

GRIFFITH en su libro The Politics of the Judiciary ${ }^{6}$ decía que los jueces deberían ser independientes, pero no pueden ser políticamente neutrales, en tanto en cuanto ocupan posiciones a diario que les exigen o requieren pronunciamientos acerca de lo que es el bien común, el principio de proporcionalidad, el interés general, el concepto de propiedad privada, la dimensión de la vida o la interpretación del matrimonio...

La reforma de 2013 del Consejo General del Poder Judicial en España se fraguó en un clima político que anhelaba "regeneración democrática" y que estaba cargado de propuestas, articuladas en la Ley orgánica 4/2013 de 28 de junio. Poco después fue reformada por Ley orgánica 7/2015, de 21 de julio, reforma que fue recurrida ante el Tribunal Constitucional y que la sentencia 191/2016 de 15 de noviembre salvó en su totalidad a pesar de haber construido una jurisprudencia que apostó por una cómoda "interpretación conforme"

taria de hombres y mujeres en los vocales del Consejo; d) se recuperan algunos elementos del viejo consejo de 2013.

${ }^{4}$ LUCAS MURILLO P., La independencia y el gobierno de los Jueces. Un debate constitucional. Discurso de recepción del Académico de número, 23 de mayo 2017, pág.143-144.

5 ANDRES IBAÑEZ P., El tercero en discordia, Editorial Trotta, 2015, pág. 160-161;

${ }^{6}$ GRIFFITH J.A.G., The Politics of the Judiciary, Fifth Edition 1997, pp. 260 y ss.

7 MARTINEZ ALARCON M.L., "El Tribunal Constitucional avala la constitucionalidad de la reforma del Consejo del año 2013. La Sentencia 191/2016, de 15 de noviembre. Revista General de Derecho Constitucional, $\mathrm{n}^{\circ}$ 24, IUSTEL 2017; 
Y hoy, en pleno proceso de renovación del órgano de gobierno de jueces y magistrados, la prensa ya ha anunciado ${ }^{8}$ quién será el próximo presidente del Tribunal Supremo, esto es, y del Consejo a su vez. Sin que hayan tomado posesión los vocales pactados por las fuerzas políticas para constituir el pleno. Un pleno que es, según la Ley orgánica del Poder judicial (art. 599.1ㅇ, 2), el que debe elegir y votar a su presidente. Hoy vivimos un claro bloqueo de la renovación del Consejo y una incertidumbre política y normativa sobre cómo y quién renovará nuestro órgano de gobierno.

Sumado a este escenario, se está debatiendo en la Comisión de Justicia de nuestro parlamento, una nueva reforma de la LOPJ que recupera en parte el Consejo anterior a 2013. Dos grandes razones amparan la proposición de ley: por un lado, “...reformas que se consideran adecuadas a fin de que el órgano plenario del Consejo General del Poder Judicial encarne más fielmente las funciones que el artículo 122 CE le encomienda..."; y, por otro, "se incorporan al estatuto de los integrantes de la carrera judicial las reformas que vienen impuestas por compromisos internacionales en materia de transparencia y lucha contra la corrupción y señaladamente las referentes al régimen de los cargos de nombramiento discrecional..."9

Regeneración, incertidumbre, conflicto político, versiones contradictorias sobre nuestro órgano de gobierno. Críticas desde las instituciones internacionales acerca de nuestros jueces y nuestro Consejo ${ }^{10}$.

Y, en medio de este proceso y en el Reino Unido, se reforma el Poder judicial, con unos problemas muy similares, en el complejo escenario de su proceso de Brexit, (fruto del referéndum de 23 de junio de 2016) en un modelo de unwritten constitution, con una tradición de common law. ¿Cómo y porqué este país ha reformado, tan profundamente, su Poder Judicial y sus procesos de nombramientos de su Judicatura? ¿Qué reflexiones o lecciones podemos aprender de ello?

La esencia de la reforma inglesa se articula a través de la Constitutional Reform Act de 2005 (CRA) que entre sus contenidos aborda tres aspectos básicos:

a) La modificación de Lord Chancellor ${ }^{11}$ (Ministro de Justicia y antigua cabeza de la Judicatura inglesa y, antes también, Speaker de la Cámara de los Lores), en sus competencias, en sus funciones y, en definitiva, en su rol a desempeñar en el marco de los poderes institucionales británicos.

8 "Manuel Marchena presidirá un Poder Judicial con mayoría progresista”, Diario El País, 13 noviembre de 2018; Unos días después, la prensa anuncia: "El juez Marchena renuncia a presidir el CGPJ tras el polémico WhatsApp del portavoz del PP en el Senado", Diario Público 20 noviembre 2018;

9 BOCG, SENADO apartado I, núm. 295-2273, de 7 noviembre de 2018, Proposición de Ley orgánica de reforma de la Ley Orgánica 6/1985, de 1 de julio, del Poder Judicial (Congreso de los Diputados, Serie B, núm. 166, núm. Expediente 122/000133)

${ }^{10}$ CAMISÓN YAGUE J.A., SORIANO MORENO S., "Informes de Resultados de 2016 y 2017 sobre las recomendaciones propuestas por el GRECO para la prevención de la corrupción judicial en España: crónica de incumplimientos” en Teoría y Realidad Constitucional, núm. 41, UNED 2018, pág. 337-356.

11 WOODHOUSE D., "The Constitutional Reform Act 2005-defending judicial independence the English way", I-CON, International Journal of Constitutional Law, vol. 5, issue 1, January 2007, pp. 153 y ss.

(C) UNED. Revista de Derecho Politico

N.o 107, enero-abril 2020, págs 71-109 
b) La creación del Tribunal Supremo del Reino Unido en $2009^{12}$ y la consiguiente abolición de la Court of Appeal de la House of Lords; así como la nueva jurisdicción del Judicial Committe of the Privy Council y las nuevas funciones en materia judicial del Presidente del Consejo.

c) Y, en tercer lugar, la creación de un nuevo órgano al que se le atribuye el procedimiento de nombramiento de los Jueces: la Judicial Appointment Commission (JAC). Y que viene a erradicar, de manera clara, el antiguo procedimiento de nombramiento de jueces: "tap on schoulder", incompatible desde luego con el artículo 6, párrafo primero de la Convención Europea de Derechos Humanos. La JAC comenzará a funcionar en 2006 y, diseñada inicialmente como un órgano de selección e identificación de candidatos, está funcionando en la práctica como un verdadero órgano de nombramiento.

La perspectiva o metodología comparada constituye, como muchos autores han puesto de relieve, un activo incontestable y de manera aún más especial en Derecho constitucional. Pizzorusso habla del "patrimonio cultural europeo"13, Armin von Bogdandy considera que a los retos del constitucionalismo del siglo XXI se debe responder desde la "arena legal europea" ${ }^{14}$ y el propio Mark Tushnet explica que los límites nacionales o fronterizos: legales, políticos, geográficos o económicos se han diluido o desdibujado ${ }^{15}$. Todos ellos coinciden en la convergencia y la necesidad de construcción de un "European constitutional heritage". Juristas, politólogos, legisladores y académicos deben y pueden contribuir a este patrimonio común.

DIEZ-PICAZO L. M., a finales del siglo pasado, entiende que el marco de análisis de la independencia judicial no puede ser otro que el comparado, y enuncia dos modelos de independencia judicial: el anglosajón y el europeo-continental. Y resulta interesante comprobar que la elección de los jueces es el primer eslabón en el diseño institucional/funcional de la independencia. Con tales premisas resultaba interesante comparar dos modelos de Poder Judicial tan distintos, civil law y common law, en un aspecto concreto: los procesos de selección de Jueces de la JAC y los nombramientos discrecionales del CGPJ.

El Consejo General del Poder Judicial sigue siendo uno de los "asuntos pendientes” para ciudadanos, políticos, juristas, jueces, magistrados y, desde luego, académicos. Prueba de ello son los programas electorales de los Partidos políticos o los trabajos de la Subcomisión parlamentaria ("Subcomisión de Estudios y Definición de la

12 LE SEUR A., Building the UK'S new Supreme Court. National a comparative perspective. Oxford 2004

13 PIZZORRUSO A., Il patrimonio costituzionale europeo, Il Mulino 2002, páginas 14 y ss.

14 BOGDANDY VON A., "The past and present of doctrinal constructivism: a strategy for responding to the challenges facing constitutional scholarship in Europe", ICON (International Journal of Constitutional Law), n. 7, 2009, n.3, pp. 364-400.

15 TUSHNET M., "The boundaries of Comparative Law", EuConst (European constitution Law Review), n. 13, 2017, pp. 12 y ss. 
Estrategia Nacional de Justicia" creada el 1 de marzo del 2017) sobre estos temas o, también las muchas publicaciones que los analizan ${ }^{16}$.

La independencia Judicial requiere un modelo institucional que funcione, requiere unos jueces "independientes" y "justos"17, con unos procedimientos capaces de nombrarlos. Se logra con un ejercicio del poder Judicial "responsable" en una doble dimensión (política y jurídica; accountability) y ello sin merma alguna de su independencia. Y para ello será imprescindible un poder Judicial legítimo, representativo de nuestra sociedad, justo, efectivo y eficiente. Un poder basado en el mérito, capacidad y especialidad e idoneidad de sus Jueces y Magistrados.

El Juez-funcionario que escala la carrera judicial (juez español) y, por otro lado, el profesional del Derecho prestigioso y experimentado (juez británico) que como premio y reconocimiento a su carrera decide ejercer la función jurisdiccional, se deben a un poder judicial que tiene que ser independiente ${ }^{18}$.

Estas líneas pertenecen a un proceso o ejercicio de "comparación” entre dos modelos muy distintos de poder Judicial y dos concepciones de Judicatura también completamente diversas, somos conscientes de que los "frutos" de tal comparación son flexibles, pero desde luego inspiradores y útiles. Nuestras conclusiones son: "penúltimas conclusiones" que atisban los resultados de esta investigación de Derecho Comparado.

\section{LOS PROCESOS DE NOMBRAMIENTOS REGLADOS Y “DISCRECIONALES” EN ESPAÑA.}

El 17 de marzo de 2017 la Plataforma Cívica por la independencia Judicial planteaba así de rotunda la siguiente cuestión al presidente del Consejo General del Poder Judicial, el señor Carlos Lesmes, ¿Hay amiguismo en los nombramientos discrecionales? ${ }^{19}$ Entre las respuestas que el presidente del órgano dio anunció la intención de

16 AGUIAR DE LUQUE L., "Las recientes reformas en materia de Poder Judicial en su dimensión orgánica” (REVENGA SANCHEZ M., coord.), El Poder Judicial VI Congreso de la Asociación de Constitucionalistas de España, Madrid 2009; AGUIAR DE LUQUE L., El gobierno del Poder Judicial. Una perspectiva comparada, CEPC, Madrid 2012; AULET BARROS J.L., Jueces, política y justicia en Inglaterra y España, Barcelona, Cedes 1998. HERNÁNDEZ GARCÍA J., "La inaplazable necesidad de reforma del sistema de nombramiento de Altos cargos judiciales”, Revista Vasca de Administración Pública, núm. 77, 2007, páginas 39 y ss. IÑIGUEZ HERNÁNDEZ D., El fracaso del Autogobierno judicial, Thomson Civitas, Madrid 2008. JACKSON VICKY, "Judicial Independence: structure, context, attitude" in Judicial Independence in transition, ANJA SEIBERT-FOHR, eds. Lydia Friederke Müller [et al.] Heidelberg, Springer 2012. SORIANO GARCIA J.E., El Poder, la Administración y los Jueces (A propósito de los nombramientos por el Consejo General del Poder Judicial), IUSTEL 2012.

17 GRAEME WILLIAMS QC, A short book of Bad Judges, UK 2013, pp. 4 y ss.

18 DIEZ-PICAZO L. M., "Notas de Derecho comparado sobre la independencia judicial", en Revista española de Derecho Constitucional, año 12, no 34, enero-abril 1992, págs. 29 y ss.

19 BERBELL C. "La PCIJ a Lesmes: ¿hay amiguismo en los nombramientos discrecionales del CGPJ?”, Confilegal 17 de enero de 2017: https://confilegal.com/20170117-la-pcij-lesmes-amiguismolos-nombramientos-discreccionales/

(C) UNED. Revista de Derecho Politico 
un nuevo reglamento que, en el ánimo de erradicar tales sensaciones de arbitrariedad de los nombramientos, debería tener presentes tres factores: la trayectoria profesional del juez, su evaluación en el desempeño de su carrera y la especialización. Nombrar discrecionalmente, más allá del acceso a la carrera judicial (proceso éste completamente reglado), es la llave maestra de nuestra independencia judicial. Necesaria y peligrosa, discrecionalidad "divino tesoro..." de nuestra carrera judicial.

El punto de partida es el artículo 599.4 de la LOPJ que asigna al pleno del CGPJ como competencia exclusiva todos los nombramientos o propuestas de nombramientos que impliquen algún margen de discrecionalidad ${ }^{20} 0$ apreciación de méritos. La propuesta es del Consejo, el nombramiento del Pleno, el acto administrativo del nombramiento requiere como elemento formal y material la "motivación" ${ }^{21}$. Y tal acto administrativo tanto en el fondo como en la forma puede ser recurrido ante el Tribunal Supremo, de ahí que sea a través de la jurisprudencia de este órgano como inductivamente podamos estudiar la evolución y problemas pendientes de los nombramientos discrecionales. Las críticas son y siguen. SORIANO critica duramente al Consejo por su margen de discrecionalidad tan laxamente entendido, que provoca una "hemorragia de indignidad"22. ANDRÉS IBAÑEZ ${ }^{23}$ ha explicado que es tarea obligada y necesaria "moralizar" y racionalizar la política de nombramientos discrecionales, que fluye en un contexto de ausencia de regulación y de falta de control de una abrumadora discrecionalidad apoyada más bien en factores como oportunismo político, discriminación en función de la pertenencia asociativa, o posicionamiento ideológico.

\section{a) Las competencias del Consejo General del Poder Judicial en materia de nombramientos.}

Dentro de todas las competencias que tiene atribuidas el Consejo (art. 560 LOPJ), una de ellas es su capacidad de "nombramiento" de Jueces y magistrados. Todos los nombramientos que tienen lugar en el seno del Poder judicial podrán ser reglados o discrecionales. Fuera de los reglados, se encuentran los que se han denominado "nombramientos discrecionales" y todos ellos se pueden agrupar en tres categorías o grupos de nombramientos:

${ }^{20} \mathrm{El}$ asunto de la discrecionalidad y de los actos políticos del gobierno es un tema complejo; “....acto discrecional por excelencia: el acto político. A partir de una determinada interpretación del principio de separación de poderes, hasta no hace mucho incluso el acto discrecional no era susceptible de control por los jueces por entender que tal criterio fundante del Estado de Derecho impedía que un poder del estado pudiera enjuiciar losa actos de otro poder del Estado [ ] tal afirmación de irrecurribilidad, de ausencia de control, de ámbitos propios dónde no es posible que entre el poder judicial, no parece que pueda mantenerse en un Estado de Derecho...” RODRÍGUEZ-ARANA MUÑOZ J., Derecho Administrativo español, Netbiblo 2008, pág. 14 y ss.

21 IGARTUA SALAVERRIA I., La motivación en los nombramientos discrecionales, Cuadernos Civitas, Thomson Civitas 2007.

${ }^{22}$ SORIANO GARCÍA J.E., op. Cít., págs. 288 y ss.

23 ANDRÉS IBAÑEZ P., "Racionalizar (y moralizar) la política de nombramientos", Jueces para la Democracia, $\mathrm{n}^{\circ}$ 52, 2005 páginas 12-15; 
a) El nombramiento del Presidente del Tribunal Supremo y al mismo tiempo del Consejo General del Poder Judicial (art 599 LOPJ). El candidato será elegido por el Pleno del Consejo en su sesión constituyente y debe obtener una votación favorable de tres quintos, calculados, sobre los 21 miembros totales del CGPJ (12,6 lo que significa trece votos a favor). Será nombrado por el Rey, mediante Real Decreto refrendado por el Presidente del gobierno.

b) Nombrar a los magistrados del Tribunal Supremo y a los Presidentes de Tribunales y Sala, ello mediante Real Decreto y refrendado por el Ministro de Justicia.

c) Nombrar al Vicepresidente del Tribunal Supremo, al Secretario General, al Vicesecretario General del CGPJ, al Promotor de la Acción Disciplinaria, al Jefe de Inspección de los Tribunales, al Director de la Escuela Judicial y a sus profesores, al Director del Centro de documentación judicial, así como a su personal. Y, por último, al Director del Gabinete Técnico y demás personal de los servicios administrativos.

Asimismo, y de manera general, como el artículo 599.1. $4^{\circ}$ LOPJ establece que el pleno será competente para todos los nombramientos o propuestas de nombramientos o promociones que impliquen algún margen de discrecionalidad o apreciación de méritos, resulta decisivo el Reglamento 1/2010 aprobado por acuerdo del Pleno del Consejo de 25 de febrero de 2010. Este cuerpo normativo de naturaleza reglamentaria acota, limita y "da esplendor" (como la Real Academia de la lengua) al necesario, cómodo y político concepto de "discrecionalidad".

En el Reglamento se regula la provisión de plazas para los nombramientos discrecionales de los órganos judiciales. Los nombramientos son, por tanto, competencia del Consejo, pero resulta evidente que los problemas serán distintos respecto de los distintos tipos de nombramientos. El Tribunal Constitucional, en sentencia 108/1986, de 29 de junio, expresaba: “... las funciones que obligadamente ha de asumir el Consejo son aquellas que más pueden servir al Gobierno para intentar influir sobre los Tribunales: de un lado, el posible favorecimiento de algunos Jueces por medio de nombramientos y ascensos; de otra parte, las eventuales molestias y perjuicios que podrían sufrir con la inspección y la imposición de sanciones. La finalidad del Consejo es, pues, privar al Gobierno de esas funciones y transferirlas a un órgano autónomo y separado. ..." (F.J.7º)

\section{b) La evolución de la Jurisprudencia de los "nombramientos discrecionales".}

El abanico argumentativo de los fallos del Tribunal Supremo estudiados desde el año 2006 oscila entre dos opciones extremas que deben evitarse: ni convertir los nombramientos discrecionales en un puro "concurso de méritos" reglado al máximo (pues en este caso estaríamos destruyendo el carácter y esencia de la naturaleza discrecional querida) y, tampoco, equiparar nombramientos discrecionales con "cargos de confianza" permitiendo una laxitud ad infinitum. 
LUCAS MURILLO explica que un magnífico magistrado puede ser un pésimo gestor de un tribunal. [...] Y también puede darse el caso de que quien acumule numerosos méritos de esa naturaleza no sea el que más destaque por la calidad de sus sentencias. Ello es argumento irrefutable de una necesaria y justificada discrecionalidad. ${ }^{24}$ MARIANO BACIGALUPO en su análisis de la jurisprudencia del Supremo destaca que no debe ser confundida "discrecionalidad técnica" con la "libre designación" que era lo que se venía haciendo en los primeros fallos de finales del siglo XX, extremo peligroso refugio de conveniencias políticas. ${ }^{25}$

$\mathrm{Y}$, ¿qué comporta o en qué se apoya la discrecionalidad, ¿qué busca o hacia dónde debe enfocarse?

1. Primera etapa: el abandono de la tesis del "cargo de confianza"26.

La idea pionera de estas primeras sentencias a partir de 2006 fue descartar que el argumento de la confianza en el candidato pudiera ser suficiente tanto para erradicar el oportunismo político, como para garantizar el mérito y la capacidad. Desde entonces el CGPJ tendría libertad de actuación como órgano constitucional. La libertad se limitaría mediante los principios de mérito y capacidad que se interpretarían a la luz de la Ley orgánica 3/2007 de 23 de marzo de igualdad efectiva de hombres y mujeres. En estos años se hizo especial hincapié en la diferenciación entre plazas de naturaleza jurisdiccional, de naturaleza gubernativa y de naturaleza mixta jurisdiccional-gubernativa ${ }^{27}$. No es lo mismo ejercer sin más la función de la iuris dictio, que gobernar una Sala o un órgano colegiado concreto. Los requerimientos o demandas de una y otras tareas son, claramente, distintas. De ello da clara cuenta el Reglamento de 2010 años más tarde.

2. Segunda etapa: nueva pedagogía en la motivación de los nombramientos ${ }^{28}$.

El Tribunal se dedica a "abundar" sobre qué es y qué pasos deben seguirse para lograr una adecuada motivación. Y así habrá que identificar qué criterios fueron seguidos o preestablecidos por el Tribunal Calificador del concurso para la pondera-

24 MURILLO DE LA CUEVA P., La independencia y el gobierno de los jueces. Un debate constitucional. Discurso de entrada a la Real Academia de Ciencias Morales y Políticas, Madrid 23 de mayo de 2017, pág. 72;

25 BACIGALUPO SAGESSE M., "En torno a la motivación de los actos discrecionales emanados de los órganos colegiados: ¿Debe el Consejo General del Poder Judicial motivar los nombramientos judiciales de carácter discrecional?", Revista Española de Derecho Constitucional, no 107, páginas 408 y ss.

26 SSTS 5 julio 2004, sección $7^{\text {a }}$, recurso 1282/2000; 3 marzo 2005, sección $3^{\text {a }}$ recurso 260/2004; 29 mayo 2006, núm. 309/2004;

27 Artículo 2.2 del Reglamento de 2010.

28 DEL GUAYO CASTIELLA I., "Los nombramientos judiciales discrecionales y su motivación: nacimiento evolución y expansión de una jurisprudencia del Tribunal Supremo (2006-2011)”, Diario LaLey, Wolters Kluwer, nº 7907, 23 julio 2012, Año XXXIII. 
ción y valoración de los méritos; expresar qué méritos de entre todos los que hizo constar en su solicitud de participación en el concurso son considerados, clarificando también los excluidos y explicando la puntuación otorgada.

El Acuerdo de 25 de junio de 2008 añadía un párrafo segundo al art. 46 del Reglamento de Organización y Funcionamiento del CGPJ de 1986. “en los Plenos que decidan las propuestas de nombramientos de cargos judiciales, se dejará constancia de la motivación del acuerdo, con expresión de las circunstancias de mérito y capacidad que justifican la elección de uno de los aspirantes con preferencia sobre los demás. La motivación podrá hacerse por remisión, en lo coincidente, al informe elaborado por la CC (en la actualidad Comisión permanente) ...” Para ajustarse a las exigencias del acuerdo se aprueba el Reglamento 1/2010, de 25 de febrero que "regula la provisión de plazas de nombramiento discrecional en los órganos Judiciales" (BOE, $\mathrm{n}^{\circ} 56$, 5 de marzo de 2010).

3. Tercera etapa marcada por la aparición del Reglamento 2010 y una mayor profundización en la motivación.

El Reglamento de 2010 nace con vocación “integral”, garantizando la seguridad jurídica y la igualdad, pero de modo compatible con la idoneidad y especialización previstas en el artículo 326.1 de la LOPJ. En este precepto radica la esencia de la "discrecionalidad" cuyo más nítido límite es la arbitrariedad. La discrecionalidad no es jurídicamente unívoca. La libertad de apreciación o de juicio que puede llevar a cabo el CGPJ no le exime, en ningún caso de hacer públicos sus criterios y de poner éstos en relación coherente y apropiada con el tipo de plaza a cubrir. El reverso del nombramiento es la forma, el procedimiento o desarrollo procesal a seguir para la provisión de la plaza. De este modo se ordenan, las convocatorias de las plazas vacantes, las solicitudes de quienes aspiren a ocuparlas, las propuestas motivadas de la Comisión permanente y los acuerdos del Pleno..." Homogeneidad de forma es seguridad, es transparencia, es igualdad.

a) Fase de publicación de vacantes (art. 12 del Reglamento 1/2010).

En primer lugar, se publica la plaza en el Boletín Oficial del Estado y se concede un plazo de seis meses, desde la publicación, para su resolución definitiva. Las "bases" de la convocatoria deben ser aprobadas por el Pleno del Consejo. Cuando la plaza no es estrictamente judicial, se añade un elemento que tiene profunda y clara naturaleza "política" que es la exposición por el candidato "del programa de actuación que estimen adecuado a las características de la plaza solicitada desde el punto de vista organizativo y de funcionamiento..." Conocer los extremos de la plaza vacante convocada es inyectar "luz y taquígrafos" al proceso desde el inicio. Perfilar y/o detallar qué se busca es, en cierto modo, limitar qué candidatos no serían adecuados. 
b) Fase de solicitudes por parte de los candidatos (arts. 13, 14 y 15 del Reglamento) que dispondrá de un plazo de veinte días desde la publicación en el BOE.

c) Fase ante la Comisión permanente (art. 16 del Reglamento), que añade una exigencia de "comparecencia".

Esta manera desdoblada de estructurar el procedimiento ante la comisión permanente y el pleno convierte sendas fases en partes separadas, tales como propuesta y nombramiento, conveniente separación frustrada en la práctica. Entre la comisión permanente y el Pleno no hay oxígeno, ni aire fresco que respirar. La comisión permanente está presidida por el presidente del Consejo y es una parte reducida del pleno. Una parte que tras la reforma de 2013 tiene un estatus especial respecto de los demás vocales y que durante un año (después debe rotar para dar participación al resto de vocales), ostenta un papel decisivo dentro del Consejo ${ }^{29}$.

Por otro lado, el reglamento se refiere al régimen de comparecencias de los candidatos y resulta injustificado no exigir "comparecencia" para la explicación de los méritos y demás extremos, si las plazas a cubrir son distintas de las de las Salas del Tribunal Supremo (salvo si se van a cubrir por Abogados y juristas de reconocida competencia).

La reforma del reglamento de $2013^{30}$ comienza explicando que la experiencia acumulada desde 2010 con las comparecencias ha sido muy positiva, una herramienta utilísima para combatir la falta de transparencia, la potencial arbitrariedad y cualquier atisbo de separación de los principios de mérito y capacidad. Se busca reforzar la comunicación y el conocimiento de las trayectorias profesionales y méritos, de boca del candidato; se busca oír, de primera mano, su sentido de la función jurisdiccional y su visión de la experiencia profesional en el ejercicio. ¿Y entonces, porque las plazas de magistrados a las Salas del Tribunal Supremo no están sometidas al régimen general de comparecencias? Unas comparecencias que son en audiencia pública, que permiten turno de preguntas y/o aclaraciones requeridas por los vocales presentes, de las que se levantará un "acta sucinta".

Una vez celebrada la comparecencia, la comisión permanente elevará al Pleno una propuesta motivada de tres candidatos. Deben explicarse las "fuentes" o materiales empleados para conocer tales méritos. Se adjuntará un resumen de los trámites e incidencias y se redactará la "plena justificación" de la propuesta, poniendo de relieve que no ha habido discriminación por

29 DONAIRE VILLA F., «La renovada configuración de la Comisión Permanente del Consejo General del Poder Judicial tras la ley orgánica 4/2013» en Independencia Judicial y Estado Constitucional. El Gobierno Judicial, Aguiar de Luque L., (editor), Tirant monografías 988, Valencia 2016, pp. 53 y ss.

30 Acuerdo de 7 de marzo de 2013, del Pleno del Consejo General del Poder Judicial, por el que se modifica el Reglamento $1 / 2010$, de 25 de febrero que regula la provisión de plazas de nombramiento discrecional enlos órganos judiciales, BOE n 74,27 marzo de 2013, pp. 24221 a 24224. 
razón de género. Junto con la lista de peticionarios a cubrir la plaza vacante se permite a cada vocal del Consejo incluir a otros miembros o candidatos que serán también considerados y escuchados.

d) Fase final de nombramiento ante el Pleno del Consejo General del Poder Judicial (arts. 17 y 18 del Reglamento).

Sobre la terna elevada al Pleno, éste deberá votar y llegar al nombramiento final. La votación en el Pleno se acoge al nuevo régimen de adopción de acuerdos tras la reforma de 2013 . Y ello camina en sentido inverso a la reforma de la Ley orgánica 2/2004, de 28 de diciembre: “...el incremento de la mayoría a tres quintos — computada sobre la totalidad de los veintiún miembros que componen el Pleno al margen de coyunturales o definitivas ausencias o ceses - evitará la tentación, ahora y en el futuro, de decidir tan importantes nombramientos conforme al criterio de una mayoría estable concreta pero institucionalmente insuficiente, sustituyendo esta práctica por el diálogo y el consenso permanente..."

El salto desde esta reforma del año 2004 hasta el modelo "Lesmes" de palo $y$ zanahoria ${ }^{31}$ actuando a través de la fácilmente manejable comisión permanente es evidente. Según el artículo 630.1 de la LOPJ, los acuerdos del pleno con carácter general y salvo que la ley expresamente proponga otra mayoría se adoptarán por mayoría simple de los miembros presentes. El artículo 129 de la LOPJ exigía al Pleno para que éste estuviera válidamente constituido y pudiera adoptar acuerdos un mínimo de catorce miembros con asistencia de su Presidente. La ley vigente (art 600.4 LOPJ) con carácter general, establece un mínimo de diez vocales y su Presidente para considerarlo válidamente constituido. En definitiva, donde antes se exigían ocho votos, ahora serán suficientes seis ${ }^{32}$.

4. Cuarta etapa: la peligrosa doctrina del control judicial funcional. Un intento fallido de justificar el nombramiento en los "modos de proceder" obviando el fondo de estos.

Varias sentencias previas de $2011^{33}$ desembocaron en esta jurisprudencia del control funcional que supuso un intento de "marcha atrás" en lo que se había consolidado hasta el momento. "...en el sentido de que cumplidas unas formas que, si no

31 Diario ABC de 18 de marzo de 2014: "Lesmes enciende a los Jueces al decir que se les controla "con palo y zanahoria"; Diario El Mundo, 17 marzo de 2014, "No veo causas que justifique indultar a los condenados por corrupción";

32 FERNÁNDEZ RIVEIRA R.M., op. Cit., pág 169. Este artículo 630.1 LOPJ, se vuelve a cambiar con la reforma de la LO 4/2018, 29 de diciembre.

33 SSTS 4 febrero 2011, núm. 588/2009; 7 febrero 2011, núm. 343/2009; 7 febrero 2011, núm.337/2009; 7 marzo 2011, núm. 570/2009; 7 abril 2011, núm.277/2009; 12 abril 2011, núm.261/2009; 17 mayo 2011, núm.143/2010;

(C) UNED. Revista de Derecho Político 
óptimas, sí permitan detectar con suficiencia los datos y razones que movieron las decisiones del Consejo, nos pronunciemos concluyentemente sobre la legalidad o ilegalidad de fondo de esta.

Sería algo así como que los medios justifican cualquier fin y si el procedimiento seguido es acorde a lo requerido, da igual que no haya motivación bastante o coherente, lo básico será la manera de proceder.

Varios votos particulares resultaron muy críticos con esta línea abierta y así LUCAS MURILLO DE LA CUEVA señaló: “...la idea de control funcional que defiende y aplica esta sentencia no concuerda con la jurisprudencia de referencia ni, lo que es más importante, con los principios en los que descansa”; y GARZÓN HERRERO: “... hemos modificado en una tarde, una jurisprudencia laboriosamente establecida durante años. [...] la sentencia ha abdicado de la función controladora de la actividad administrativa que le corresponde, no ha garantizado los derechos impetrados y ha conseguido extralimitaciones de la Administración al carecer el acto impugnado de motivación suficiente..."

Esta peligrosa línea, en opinión de GIL CREMADES ${ }^{34}$, se fue apagando y sólo perduró en algún otro fallo de 2011. Una doctrina interpretativa, la de la fiscalización de los nombramientos discrecionales por la vía de un control de los motivos por los que se propusieron, basada en "los motivos subyacentes implícitos y el control judicial funcional” que afortunadamente tenía los días contados.

\section{EL SIGNIFICADO DE LOS PROCEDIMIENTOS DE SELECCIÓN DE LA JUDICATURA PARA LA INDEPENDENCIA JUDICIAL.}

Según los datos del European council about efficiency of the Justice in Europe CEPEJ publicados en $2016^{35}$ la calidad y eficiencia de la Justicia depende de: a) las condiciones del "reclutamiento" y "formación" de los jueces; b) del número de Jueces en cifras que analizan: jueces por habitantes, jueces mujeres y hombres en la totalidad de la judicatura, jueces en los distintos órganos y niveles jerárquicos, jueces en las diversas jurisdicciones y procesos, etc.; c) de las condiciones que configuran el "estatus" que garantiza su independencia; y d) del número de "personal/staff” que está trabajando con ellos en el órgano judicial o directamente como asesor o asistente en el ejercicio de la actividad jurisdiccional.

${ }^{34}$ GIL CREMADES R., "Un giro jurisprudencial histórico: el Tribunal Supremo abandona su doctrina de que en la función administrativa no hay que justificar los nombramientos para puestos de libre designación”, Revista Vasca de Administración Pública, n. 99-100, Mayo-diciembre, 2014, páginas 1570 y ss.

35 European Council about efficiency of the Justice in Europe, $\mathrm{n}^{\circ} 23 \mathrm{CoE}$. "I began my career as a single mum': female QCs changing the face of law”, The Guardian, 19 January 2018: “...Only 7.1\% of currently practising QCs come from black and minority ethnic (BAME) backgrounds...” 
Pues bien, en medio de tales cifras y del escenario descrito a lo largo de la jurisprudencia analizada podemos concluir ciertos logros y varios aspectos aún pendientes en aras de nombramientos discrecionales independientes, justos, efectivos y eficientes.

\section{A) La intención real y consciente de sustanciar una "necesidad de cambio".}

Se abandona ya ese momento de la "discrecionalidad técnica" ${ }^{36}$, del "cargo de confianza”, que siendo un lugar común de gran laxitud surgió para contrarrestar el aparato burocrático represivo del régimen anterior a la democracia. Discrecionalidad hoy en día, en un sistema democrático, en ningún caso puede permitir nombramientos amparados en irregularidades, ambigüedades o arbitrariedades inmunes al control, de manera especial, al control judicial.

\section{B) La necesidad de motivación clara, expresa y suficiente.}

La libertad de actuación del consejo debe estar sujeta a ciertos límites que quedarán sin duda plasmados en el informe. Tales límites son el principio de igualdad, mérito y capacidad, a ellos deben sumarse condiciones de idoneidad y especialización, que como tales cuentan con unos contenidos claros fijados a lo largo de los años y ciertamente consolidados. Por ejemplo, para ser magistrado del TS se habla de la "solvencia y excelencia en el ejercicio de la estricta función jurisdiccional". Se da un paso decisivo que es desglosar el contenido de una adecuada motivación sobre todo cuando se fije una puntuación máxima estableciendo el valor relativo de cada uno de los méritos y explicando de qué manera se ha llegado a los diversos resultados.

\section{C) El informe debe respetar unos contenidos y unas formas.}

El informe debe: “...contener una descripción de las fuentes de información que han sido utilizadas [...] también deberá consignar los específicos criterios de mérito y capacidad que han sido considerados preferentes para elaborar la relación de candidatos que es elevada al Pleno [... ] segundo, que los datos y hechos que encarnen ese soporte material se establezcan con criterios objetivos de búsqueda y selección que sean aplicados por igual a todos los aspirantes".

Después de 2008, ha habido otros fallos que han matizado aquella jurisprudencia en tres aspectos importantes, a saber: a) no se puede exigir el mismo nivel de solvencia y de excelencia, ni el mismo patrón de exigencia, en el nombramiento de un presidente de una Audiencia y en el de un magistrado del TS; b) el máximo nivel de valoración y ponderación o apreciación por parte del CGPJ está en el nombramiento

36 BACIGALUPO SAGESSE M., op. cit.;

(C) UNED. Revista de Derecho Politico 
de magistrados del TS y, c) el canon de motivación plantea como "decisivo" que sean bien visibles y claras las razones que han llevado al CGPJ a efectuar tal nombramiento.

\section{D) La diferente problemática de los nombramientos según los niveles jerárquicos de acceso a la Judicatura: "Jueces" y "Altas instancias" (Magistrados y Magistrados del TS) de la misma.}

Los nombramientos discrecionales son un pequeño porcentaje respecto de la totalidad de los "nombramientos. En todo este grupo señala SERRA CRISTÓBAL que son cargos o puestos de calidad o altas instancias judiciales ${ }^{37}$, es donde realmente se han planteado problemas que podrían lesionar la importante apariencia de independencia judicial y construir así una sombra inaceptable de duda sobre la necesaria garantía de imparcialidad judicial. Pero seamos honestos, el poder judicial, jerárquico, plantea problemas de independencia en los niveles superiores del mismo ${ }^{38}$.

\section{E) La explicación y desglose del "canon de discrecionalidad" que significa motivación en el} informe de la Comisión permanente, y motivación en la decisión del Pleno.

Según el artículo 43.3 del ROF (Reglamento de Organización y Funcionamiento ${ }^{39}$ del Consejo las votaciones para nombramientos se llevarán a cabo en el pleno de aquél de manera secreta, ello comporta un "óbice" insalvable en cuanto a lograr una motivación objetiva del nombramiento. ${ }^{40}$

\section{F) La diferencia entre plazas jurisdiccionales, gubernativas y mixtas discrecionales- gubernativas.}

No será igual nombrar a un magistrado del TS que al presidente de la Audiencia Nacional. Se intensifica la capacidad de valoración o discrecionalidad para ciertas plazas tal como ha explicado la jurisprudencia. Esto se perfila en la fase de convocatoria pública de la plaza (art. 12 del Reglamento 2010).

37 SERRA CRISTÓBAL R., "El Consejo General del Poder Judicial y los nombramientos discrecionales de los magistrados”, en El Poder Judicial, VI Congreso de la Asociación de Constitucionalistas de España, Coord. REVENGA SÁNCHEZ M., pág. 249;

38 El portavoz del PP del Senado se situó en el ojo de la tormenta al trascender el mensaje de WhatsApp que reenvió - no escribió — a los 146 senadores populares en el que su partido se jactaba de que, tras el acuerdo ahora frustrado con el PSOE sobre el Consejo General del Poder Judicial (CGPJ), iba a poder "controlar el Supremo desde detrás".

39 Aprobado por Acuerdo de 22 de abril de 1986 del CGPJ por el que se aprueba el ROF, BOE ${ }^{\circ}$ 107 , de 5 de mayo de 1986.

40 SERRA CRISTÓBAL R., Ibidem, pág. 265; 


\section{G) La pedagogía jurisprudencial del "informe" que debe elaborar la Comisión Permanente.}

El informe de la Comisión permanente tiene exigencias formales y materiales y ello ha tenido su reflejo en la ley orgánica del poder judicial, de ahí que apartarse del informe de la permanente por parte del Pleno del Consejo debe también ser motivado por éste. El informe limita la discrecionalidad de la Comisión permanente y del Pleno, a su vez, genera transparencia y responsabilidad.

H) La escasa presencia de mujeres en los altos cargos judiciales.

Según datos estadísticos de la memoria anual del CGPJ de 2018 las cifras son muy indicativas, en la categoría de Jueces hay 387 mujeres y 201 hombres, en la categoría de magistrados, 2.460 mujeres frente a 2.253 hombres y, en la categoría de magistrados al Tribunal Supremo, 11 mujeres frente a 65 hombres. Una judicatura representativa no debería albergar estas cifras en los niveles superiores.

\section{I) Las decisiones de la Comisión permanente ponen fin a la vía administrativa y son recurribles ante el TS si bien sorteando al pleno como tal.}

Este régimen de recursos es también "hijo" de la misma línea de Consejo autoritario y empoderador de la permanente. Las decisiones de la comisión permanente, tras la reforma de 2013, ponen fin a la vía administrativa y sólo son recurribles ante la sala de lo contencioso-administrativo del $\mathrm{TS}^{41}$. A diferencia de lo que contemplaba el antiguo artículo 143.1 de la LOPJ. Y, además, conocerá de ellos una sección especial de la referida sala compuesta por el Presidente de la Sala que la presidirá y por los demás presidentes de sección de dicha sala contencioso-administrativa. Tan sólo seis magistrados, menos incluso que la sala especial del artículo 61.

\section{J) La necesaria huida de los "extremos": que el Consejo General del Poder Judicial tome "decisiones politicas" en sus nombramientos discrecionales, ascensos y promociones no es lo mismo que aceptar una "plena politización de la justicia".}

Señalaba LÓPEZ GUERRA, Vicepresidente del CGPJ entre 1996 y 2001, que, si bien es cierto que este órgano constitucional en sus nombramientos discrecionales, ascensos y promociones toma "decisiones políticas" 42 basadas en criterios de oportuni-

${ }^{41}$ Tras la reforma LO 4/2018 el art. 602.2 LOPJ establece: "Los acuerdos de la Comisión permanente son recurribles en alzada ante el Pleno".

42 Recordamos que los nombramientos judiciales en el sistema español son "reglados" o "discrecionales", siendo estos últimos, a diferencia de los primeros, los que pueden introducir valoraciones, criterios de oportunidad y conveniencia, perfiles, etc. Ver arts. 7-11 del Reglamento 1/2010, de 25 de febrero que regula la provisión de plazas de nombramiento discrecional en los órganos

(C) UNED. Revista de Derecho Politico 
dad que no pueden ni deben quedar desligados del sujeto de la soberanía parlamentaria que será "fuente de legitimación". De manera especial, entre otras, se comprueba en los nombramientos de los Magistrados del Tribunal Supremo, órgano creador de Jurisprudencia y que desempeña "una función política que va más allá de la mera aplicación de las leyes". La selección de estos jueces por un órgano dotado de legitimación parlamentaria y representativa de las corrientes o tendencias ideológicas y políticas presentes en la sociedad permite garantizar que la creación judicial del derecho va a reflejar la tendencia presente en la conciencia social sobre el Derecho su papel. A condición, sin embargo, de que en la selección de los vocales del Consejo se evite el flujo partidista. Condición que, como es evidente, no se ha cumplido. [...] Es, por el contrario, la politización de la justicia la que ocasiona que la sociedad desconfíe de ella. ${ }^{43}$

En esta línea y al hilo del que fue el nombramiento de LÓPEZ GUERRA como vicepresidente del Consejo, MANUELA CARMENA, vocal de este durante el mismo período señalaba: “...llegamos al primer pleno del Consejo en el que había que elegir al Presidente y al Vicepresidente [...] y antes de que comenzara la votación, pedí la palabra y expliqué que estaba absolutamente en contra del pacto de los partidos..." ${ }^{4}$

Politizar la Justicia es minar su independencia oscureciendo y mermando su esencia poniéndola al servicio de "otros intereses" distraídos del imperio de la ley, pervertidores del Estado de Derecho. Aceptar la presencia de "lo político" es reconocer que dentro de la independencia judicial hay opciones, alternativas, márgenes de apreciación y diversas interpretaciones.

\section{K) La mala comprensión de la incorporación a la Judicatura de otras distintas "sensibilidades jurídicas" y el problema de las Asociaciones.}

La exposición de motivos de la LOPJ explica muy claramente, al referirse al acceso a la Judicatura siendo "juristas de reconocido prestigio”, cuáles son las pretensiones que quieren lograrse: “...incorporar a función tan relevante como la judicial a quienes, en otros campos jurídicos, han demostrado estar en condiciones de ofrecer capacidad y competencia acreditadas; por último, lograr entre la carrera judicial y el resto del universo jurídico la cohesión que, a buen seguro, se dará cuando se integren en la judicatura quienes, por haber ejercido el Derecho en otros sectores, aportarán pers-

judiciales. La última redacción de la Ley Orgánica del Poder Judicial (LO 5/2018, de 28 de diciembre) incorpora también, ante exigencias políticas de igualdad de género preceptos como el art. 567.1. "Los veinte Vocales del Consejo General del Poder Judicial serán designados por las Cortes Generales del modo establecido en la Constitución y en la presente Ley Orgánica, atendiendo al principio de presencia paritaria entre hombres y mujeres..." Estos son ejemplos de tales elementos de naturaleza "política”.

43 LÓPEZ GUERRA L., "La legitimidad democrática del Juez", Cuadernos de Derecho Público, número $1^{\circ}$, Madrid 1997, página 43-76;

44 MANUELA CARMENA, Porque las cosas pueden ser diferentes. Reflexiones de una Jueza, Clave Intelectual, Madrid 2014, páginas 97 y ss. 
pectivas diferentes e incorporarán distintas sensibilidades a un ejercicio que se caracteriza por la riqueza conceptual y la diversidad de enfoques..."

El pluralismo a que se refiere el Supremo es el que deriva de la diversa procedencia profesional de los magistrados (carrera judicial, ejercicio de la abogacía, la universidad, otras profesiones jurídicas, etc....)

Pero tradicionalmente, la práctica se encarga de denostar y pervertir el original planteamiento teórico y así con el tiempo hemos comprobado que uno de los principales problemas fue y ha sido interpretar esa buscada presencia de las distintas "sensibilidades". Varios votos particulares de PECES MORATE en SSTS de 3 febrero de 2011 y 4 febrero 2011, y dos de 7 febrero de 2011 se refieren a las "motivaciones hipócritas" y plantean acabar con un sistema de nombramientos que viene a ser un "reparto de cargos de magistrados asociados" que además trata de ningunear a los que no pertenecen a ninguna asociación que son casi la mitad.

\section{LOS NOMBRAMIENTOS DE LA JUDICATURA BRITÁNICA DESPUÉS DE LA CONSTITUTIONAL REFORM ACT DE 2005.}

El 23 de Junio de 2016 tuvo lugar en el Reino Unido el referéndum sobre el Brexit $^{45}$. Los ciudadanos británicos respondían mayoritariamente salir de la Unión Europea y comenzar una nueva etapa, aún hoy llena de incertidumbres. Una vez más, Reino Unido adquiría el mayor de los protagonismos como primer y único país de la Unión Europea que abría la puerta del "adiós" pulsando el artículo 50 del Tratado de Lisboa. Una opción nunca explorada desde que se pronunció la Declaración Schumann, allá por los años 50 .

Sólo diez años antes del referéndum, el 24 de marzo de 2005 se publicaba la Constitutional Reform Act, una ley trascendental, de profunda reforma de un modelo unwritten constitution y que articulaba (entre otros asuntos): a) la modificación de la oficina de Lord Chancellor como Ministro de Justicia, en sus competencias y función a desempeñar en el marco de los poderes institucionales británicos; b) la creación del Tribunal Supremo del Reino Unido (2009) y la consiguiente abolición de la Court of Appeal de la House of Lords, c) la nueva jurisdicción del Judicial Committe of the Privy Council y nuevas funciones en materia judicial del Presidente del Consejo y, por último, d) la creación en 2006 de un nuevo procedimiento de nombramiento de los Jueces atribuido a la Judicial Appointment Commission. Todo ello constituye una auténtica revolución constitucional que remueve el andamiaje de la separación de poderes británica.

El 1 de abril de 2003 la Asamblea Parlamentaria del Consejo de Europa a través del Comité de Asuntos Legales y Derechos Humanos adoptaba unánimemente una

$4551,9 \%$ (17.410,742 votos) votaron salir de la UE, frente a 48,1\% (16.141,242 votos) que preferían permanecer. La participación fue del 70,2\% de un censo de 46.501,241 votantes. http://www. bbc.com/news/politics/eu_referendum/results

(C) UNED. Revista de Derecho Politico

N.o 107, enero-abril 2020, págs 71-109 
clara Resolución para la oficina de Lord Chancellor en el Reino Unido. En ella, criticaba a ésta como institución acaparadora de funciones ejecutivas, legislativas y judiciales, haciendo obvio un modelo más que necesitado de reforma. Erik Jurgens ${ }^{46}$, el autor del documento, explicaba ese extraño diseño, ya clásico, en el Reino Unido que hasta 2005 concitaba en manos de tal poderosa institución: funciones ejecutivas (cabinet minister) con importantes responsabilidades en el ministerio de justicia y un papel determinante en los nombramientos de la Judicatura en su totalidad, en especial, en la Senior Judiciary; funciones legislativas de primer rango, ya que Lord Chancellor sería el Speaker de la Cámara de los Lores; y, por último, funciones propiamente judiciales al ser "Head of Judiciary" y Juez en activo ostentando el cargo de Presidente del Comité de apelación de la Cámara de los Lores (Appellate Committe of the House of Lords) y del Judicial Committe of the Privy Council.

Esta compleja reforma constitucional, en la tierra de la Carta Magna de 1215, en un Estado con Leyes constitucionales, no se produjo de modo tranquilo, sino que, sorpresivamente, fue poco a poco catapultada a la sociedad por filtraciones de la prensa. Se hacía el anuncio por el 10 de Downing Street el 12 de junio de 2003 . Una decisión de reforma tan decisiva para los años venideros surgió de la forma menos ortodoxa y esperable de una vetusta democracia moderna: "policy making on the hoof" ${ }^{47}$.

No sólo el ejecutivo en sentido extenso se sintió al margen de tal anuncio de reforma, sino que la propia Judicatura manifestó su profundo enfado como la gran damnificada y la gran olvidada también. Otros autores han interpretado el anuncio de la reforma constitucional, no tanto como algo improvisado al margen de la Judicatura sino, más bien, como una medida o manera de sortear la férrea resistencia de la Senior judiciary a ceder o, en cierto modo perder, el enorme poder acumulado.

Y como todos los momentos complejos, el carisma de las personas al frente de las instituciones constituye un incentivo o un ingrediente disuasorio. En este caso, Lord Irvine (Lord Chancellor 1997-2003) y Lord Woolf (Lord Chief of Justice 2000-2005), entre otros, supusieron largos años de laborismo (desde 1997 hasta 2010 con Blair y Brown como primeros ministros) y fueron carismas decididos a apoyar profundas reformas ${ }^{48}$.

Lo que los años han confirmado, es que el proceso sería imparable y que daría sus frutos desde el primer momento. En las páginas siguientes vamos a reflexionar tan sólo sobre uno de los aspectos que propicia la Constitutional Reform Act de 2005: el nuevo procedimiento de nombramiento de Jueces a través de un órgano independiente y no departamental del ejecutivo, de naturaleza pública y en estrecha colaboración con el Ministerio de Justicia, que tiene como función principal identificar/proponer

46 RESOLUTION 1342 (2003), Comité permanente de la Asamblea parlamentaria del Consejo de Europa, 8 de septiembre de 2003: Mr. Erik Jürgens, ANDREW LE SEUR: op. cit., pág. 3 y ss.

47 AHMED K., "Cabinet ignored over Historical Legal reforms", The Observer, 15 June 2003.

48 MALLESON KATE, GRAHAM GEE, ROBERT HAZELL and PATRICK O'BRIEN, The Politics of Judicial Independence in the UK's Changing Constitution, Cambridge University Press, London 2015, págs. 162 y ss. 
candidatos a puestos de la Judicatura en todos sus niveles, pero que la práctica, de más de diez años, ha convertido en un verdadero órgano de nombramiento judicial.

a) El viejo modelo de nombramientos judiciales "secret soundings", "tap on shoulder" ...

Señalan SHETREET y TURENNE que hablar de nombramientos judiciales es hablar de integridad e independencia judicial. Si hay buenos jueces, será en gran parte, porque los procesos han sido adecuadamente diseñados. Y solo un Poder Judicial será justo, equilibrado, independiente y eficiente si tiene "buenos" jueces ${ }^{49}$.

Una de las reflexiones más unánimes, que, durante todo el escenario previo y posterior a la reforma, tuvo lugar, fue la necesidad de modificar los procesos de selección de Jueces en el Reino Unido. La flagrante quiebra del principio de separación de poderes $^{50}$ concentrada en una única “institución”, Lord Chancellor, se hacía insostenible. Una única persona fue la máxima autoridad del Poder Judicial con las correspondientes competencias judiciales del máximo nivel. DIANA WOODHOUSE lo define como una extraña mezcla de legislativo, ejecutivo y judicial: poderes y roles ${ }^{51}$. Y llega a criticar sus funciones de más de cien años como de "broma entre intelectuales que conocen el principio de separación de poderes..." 52

Es evidente que, con el esquema descrito, los candidatos elegidos y nombrados por Lord Chancellor serían hombres de confianza del ejecutivo y cómodos colaboradores de las políticas gubernativas. Es evidente, que el viejo modelo silencioso y opaco, comprendía una relación ejecutivo-judicial poco aceptable, en la que el peso de "lo político", articulado desde los intereses propios del poder ejecutivo dirigía y configuraba quiénes ocuparían los principales puestos de la Judicatura británica. Al igual que, previamente, el nombramiento de aquél (Lord Chancellor), también de naturaleza profundamente política, se producía de entre hombres "de partido", con perfiles clásicos y en los puestos más altos de sus trayectorias político-profesionales. Señalaba GOLDSTREAM que el Primer Ministro, siempre seleccionaba para cubrir el puesto de Lord Chancellor a personas fiables, entendiendo por tal, de su partido político y de posiciones dentro de la Judicatura favorables al gobierno ${ }^{53}$.

El modelo tradicional de nombramiento de jueces, discreto y estable había sido capaz de generar buenas relaciones entre el propio estamento judicial y el ejecutivo o cabinet model, afianzando pacíficamente una manera de proceder política, legal y con

49 SHETREET S. y TURENNE S., Judges on trial. The independence and accountability of the English Judiciary, Cambridge University Press, United Kingdom 2013, pp. 102-103;

50 STEPHEN SEDLEY, Lions under the Throne, op. cit., pág. 184 y ss.

51 WOODHOUSE D., The Office of Lord Chancellor, Oxford Hart Publishing 2001, pp 39 y ss.

52 STEVENS R., The English Judges. Their role in the Changing constitution, Hart publishing OXFORD 2005, pp. 174 y ss.

53 GOLDSTREAM G., "Judicial Appointment in England", $n^{\circ} 43$, Journal of the American Judicial Society', 1959, págs. 40 y ss.

(C) UNED. Revista de Derecho Político

N.o 107 , enero-abril 2020, págs 71-109 
claras influencias provenientes de la Senior judiciary. ${ }^{54}$ Los pasos, encaminados al nombramiento, se iban dando mediante pesquisas, consultas y conversaciones tranquilas y serenas que debían sonar "lo mínimo". Secret soundings $s^{55}$, que han definido los propios británicos para tildar un proceso que debía llamar en la puerta concreta, cuando ya estaba todo urdido y decidido. Quién tenía que enterarse y dar su consentimiento recibía esa simbólica palmada en el hombro (tap on shoulder) y el proceso poco más que habría llegado a su fin.

Los pasos hacia el profundo cambio se van dando. Un recorrido difícil y complejo que culmina en la Constitutional Reform Act de 2005, el cambio será apreciable desde el primer momento. Y así, por ejemplo, en 2012 desafiando a más de cuatrocientos años de historia, llegaba a ser Lord Chancellor un hombre que no era abogado, ni jurista, ni juez. Esto ponía de relieve que las costumbres e inercias de un modelo viejo se habían dinamitado.

Entre los principales logros del nuevo modelo estaba el haber permitido el tránsito pacífico de un modelo, opaco e informal con importantes dosis de arbitrariedad y mezcla de intereses de poderes, a un modelo formalizado normativamente, limitado en su capacidad de "libre designación" y en el que la antigua discrecionalidad ministerial, sobre todo para los nombramientos judiciales del más alto nivel y posición, había quedado bastante reducida.

¿Qué procedimiento para nombrar jueces es el mejor? Difícil respuesta, desde luego. Lord Clarke señalaba que un procedimiento de selección y nombramiento de Jueces debe ser: abierto, basado en el "mérito", en la garantía del "buen carácter" de los nombrados y comprometido con la "diversidad". ${ }^{56}$

1. Los criterios de selección de los jueces deben ser públicos, claros y fácilmente comprensibles por todo tipo de ciudadanos. Para ello, ese conjunto de normas o criterios articulando el proceso deben poder ser criticados, cambiados con cierta flexibilidad y de fácil seguimiento e investigación.

54 WOODHOUSE D., The Office of Lord Chancellor, Hart Publishing Oxford, London 2001, págs. 133 y ss.

55 A pesar de todo, es curioso leer en la academia inglesa y en los principales protagonistas de todo este profundo cambio en la judicatura que el anterior modelo, no era desde luego un foco ni de corrupción, ni tampoco un cheque en blanco para nombrar "malos jueces" o jueces tan sólo por ser cercanos o próximos a las posiciones del gobierno. Lord Irvine defendió, siendo Lord Chancellor que sus modos de proceder eran altamente profesionales y efectivos, teniendo muy presente la importancia de las muchas conversaciones, entrevistas y opiniones consultadas de otros jueces muy veteranos y autorizados. Y en una conferencia en 1997 dijo: “...to the sceptic I ask, what do you think happens at one of these consultation meeting? Do you honestly believe that my Permanent Secretary turns up at a senior judge's for asking whether of Copperfield is a good chap or whether young Pickwick is a bit suspect because, rumour has it, he voted for the Green Party at the last election. Nor, our consultations are not like that..." in KATE MALLESON y RICHARD MOULES, The Legal System, Oxford 2011, pp. 216.

56 CLARKE LORD, "Selecting Judges: Merit, Moral courage, Judgment and Diversity”, High Court Quarterly Review 49, 2009, (5); 
2. Los responsables de los procedimientos de selección deben ser públicamente conocidos, en cada paso, en cada trámite, en cada informe, etc.... Para conseguir tal objetivo las opciones son variadas, por ejemplo: los currículos de los miembros de los paneles o de la JAC, de las autoridades de nombramiento, de los sujetos consultados deben ser públicos; la posible o potencial opción de mecanismos de accountability ante el Parlamento o el ejecutivo respecto del papel desempeñado por estos, también sería de gran ayuda. En el Senado de Estados Unidos se aprueba y debate, por ejemplo, el candidato a ser juez del Tribunal Supremo de los EEUU; la JAC elabora anualmente un informe dirigido a Lord Chancellor detallando todos los procesos de recomendación de jueces celebrados durante el año y las quejas que sobre los mismos hubieran podido tener lugar. Quejas que se sustancian ante un órgano llamado JACO (Judicial Appointments Commission Ombudsman); también LC debe emitir un informe escrito razonado sobre los casos de veto o reconsideración de un candidato recomendado, o incluso, rechazado. Y, por último, las personas responsables de la selección/recomendación deberían ser independientes del ejecutivo y del legislativo de ahí que sea muy importante cómo se selecciona a los commissioners y a las autoridades de nombramiento.

3. La "apertura" de los procesos para ser elegido miembro de la JAC es también decisiva. El perfil de los commissioners debe ser amplio, plural y representativo de la sociedad real. Esto otorgará importantes dosis de legitimidad a un órgano con tan relevantes competencias. Sólo así la sociedad se sentirá verdaderamente representada, sólo así se estará construyendo confianza legítima en la Judicatura como institución que presta un servicio público.

4. Un sistema de selección debe fundamentarse en el "mérito" y este concepto ambiguo y amplio ha ido mutando con los tiempos. Ello es bueno y malo al mismo tiempo. Antes de la reforma de la CRA de 2005 los criterios que definían el mérito se fijaban reglamentariamente por el Gobierno y así existe un documento de 2003 del Ministerio de Justicia especificando cuáles serían tales parámetros para ponderar el mérito de un determinado candidato. Tales criterios se han ido completando y modificando con el nuevo procedimiento ante la JAC. MORISON explica que el concepto de mérito no es algo estático, sino que como fiel reflejo de la sociedad debe ser un concepto dinámico que implemente y atienda las demandas sociales ${ }^{57}$ y que al mismo tiempo adquiera perfiles "específicos" de acuerdo a la plaza que se vaya a cubrir.

5. El "buen carácter" 58 adquiere mucho peso también como ingrediente necesario en un proceso de selección. Ahora bien, no puede ser completamente

57 MORISON J., "Beyond merit. The new challenge for judicial appointments", en Debating Judicial Appointments in an age of Diversity, op. cít., chapter 11.

58 Es interesante ver, el concepto clásico de buen comportamiento ya en el Texto constitucional más viejo del mundo actual, "Can a Supreme Court justice be forcibly removed from the bench? A quick civics lesson", The Washington Post 12 december 2015: "...Supreme Court Justice Antonin Scalia, whom my Washington Post 
delimitado en su contenido. Debe ser premeditadamente ambiguo en sus contornos $^{59}$. La previsión legislativa de una duración en el cargo mientras se acredite "good behaviour" representa una implementación anglosajona de la máxima latina quamdiu se bene gesserint.

6. Y, además, cualquier buen proceso de selección debe estar comprometido con la "diversidad". La doctrina ha reconocido muy insistentemente la gran asignatura pendiente en esta materia de los jueces británicos. KATE MALLESON habla de que especialmente en la Senior judiciary la diversidad es el "gran talón de Aquiles". Diversidad que está pensando en mujeres, en personas de color, en minorías étnicas y raciales, en colectivos formados en universidades distintas de Oxford y Cambridge, en Solicitors y no siempre en prestigiosos Barristers, etc... Una de las fortalezas de la judicatura es la experiencia de vida que los jueces llevan a sus "decisiones", esta es una buena fortaleza de la legitimidad de los jueces.

Describir el modelo anterior (Secret-sounding, Tap on shoulder) significa también contextualizar una judicatura que ha sufrido importantes cambios formales, estructurales y esenciales. La Judicatura inglesa ${ }^{60}$ profundamente individualista y convencida de que gran parte de la lucha y logros de la independencia judicial estribaba en esa tarea aislada del juez como un funcionario civil, único y sólo, concentrado en sus procesos judiciales y fallos ha cambiado. 1689 Bill of Rights (prohibiendo los Tribunales conciliares o de prerrogativa regia y dependientes del monarca), Act of Settlement de 1701 (impide la revocación de los jueces a la muerte del Rey que los nombró), Human Rights Act 1998, que establece la necesaria competencia de los jueces para interpretar derecho británico conforme a la Convención europea, el Devolution process (en Escocia e Irlanda del Norte) y sus reajustes legislativos e institucionales; la reforma de la Cámara de los Lores de 1999 (House of Lords Act) y también de sus competencias en el ámbito judicial, la propia CRA de 2005, la creación de la Supreme Court en 2009 y alguno de sus más relevantes fallos como Miller vs. Secretaría de Estado en 2016, en aras de interpretar de nuevo el principio de soberanía parlamentaria, con motivo de las negociaciones del Brexit. Todos estos eslabones han “rediseñado” la judicatura británica. El Juez inglés hoy, es otro diferente.

Aquella tradicional visión se ha valorado desde diversas perspectivas, algunos autores encuentran que aquí reside gran parte del éxito de la independencia de la

colleague Robert Barnes called "the reigning champion of provocation at the high court", just stirred up another controversy with comments about why African Americans might be better off if they are not accepted into top colleges and universities but rather to "slower-track" schools where "they do well"

59 Diversity Conference Speech, 2009, http://www.judiciary.gov.uk/docs/speech/lcj-speechdiversity-conf.pdf;

${ }^{60}$ ANDREWS N., "Judicial independence: The British Experience” in S. Shetreet and Forsyth C. (eds.), The Culture of Independence: conceptual foundations and practical Challenges, Leiden: Martinues Nijhoff, 2012; BLOM-COOPERL., DICKSON B. y DREWRY G., (eds) The Judicial House of Lords 1876-2009, Oxford: Oxford University Press, 2009; 
Judicatura inglesa, sin preocupaciones de ascender, de sus pensiones o edad de jubilación. Sólo concentrada en elaborar sentencias sólidas y justas. Pero algún sector crítico, procedente también del mundo de la Judicatura ha expuesto que esa idiosincrasia ha servido también a lo largo de los años para esconder "las cloacas de la incompetencia judicial, de la indolencia, ineficiencia, insensibilidad e ignorancia..." ${ }^{11}$ El Juez ha ido poco a poco cambiando la concepción que tiene de sí mismo, más consciente de su pertenencia a un cuerpo, el de la Judicatura, con un sentimiento corporativo vivo y en cierta medida comprometido, con percepción de relaciones jerárquicas, de la dimensión y significado de la carrera o promoción, con sentido de cuerpo con preocupaciones comunes. La relación con el ejecutivo ha cambiado, y si es cierto que aún sigue existiendo una necesaria sintonía con la Senior Judiciary a la hora de dilucidar los principales nombramientos y, de manera especial, de los 12 Jueces que componen el Tribunal Supremo, también es cierto que ahora, la burocratización del proceso, la fragmentación en etapas, la diversificación de la decisión final del nombramiento en órganos distintos y su publicidad y transparencia han articulado un modelo que no está al albur de "lo político". El nuevo modelo dialoga, coopera y limita, si es necesario, la esencia de "lo político" en los procesos de nombramientos. Este modelo es más independiente, más transparente, más confiable y más auditable. ${ }^{62}$

\section{b) La creación de la JAC Judicial Appointment Commission.}

Señalaba la Declaración de principios de del año 2004 de la Commonwealth (Commonwealth Latimer principles) en materia de separación de poderes ${ }^{63} \mathrm{e}$ independencia judicial y como referencia para los múltiples y diversos procedimientos que: “... la Judicatura de cualquier país debe ser independiente, imparcial, honesta y competente $[\ldots]$ El objetivo de cualquier proceso de selección de jueces debería ser proveer con "herramientas fiables" al sistema en el ánimo de identificar personas que posean las "cualidades" requeridas y tal búsqueda se haga de la manera legítimamente diseñada para garantizar y salvaguardar la plena "confianza pública" en la Judicatura" ${ }^{64}$

La JAC, Judicial Appointment Commission comenzó a funcionar el 3 de abril de 2006 siendo su objetivo, desde el primer momento, hacer más transparentes, efectivos y eficientes los procedimientos para nombrar Jueces en el Reino Unido. Y ello significaba sustraer poder de manos de Lord Chancellor. El presidente de la JAC es un

${ }^{61}$ WOOLF LORD, "Judicial Independence not Judicial isolation” en The Pursuit of Justice, Oxford University Press, Oxford 2008, págs. 165 y ss.

${ }^{62}$ GEE G., HAZELL R., MALLESON K., y O’BRIEN P., The Politics of Judicial Independence in the UK's Changing Constitution, Cambridge University Press 2015, pp. 9-16 y pp.182-192;

${ }^{63}$ GARCÍA ROCA J, "De la División de Poderes", Revista de Estudios Políticos, nueva época n⿳ 108 , pág. 55 y ss.

${ }^{64}$ The Appointment, Tenure and Removal of Judges under Commonwealth principles. A compendium an Analysis of Best Practice, British Institute of International and Comparative Law, 2015, pp. 15 y ss.

(C) UNED. Revista de Derecho Político 
miembro no judicial, ni jurista (un perfil laico), diseña una estrategia política y un plan de trabajo con objetivos anuales en "política de nombramientos", negociará y debatirá con el Ministro de Justicia. Este ingrediente de naturaleza estratégica-política resulta importante.

Respecto de su naturaleza, es un órgano de identificación/proposición de candidatos a las "autoridades de nombramiento" (decision-making authorities) que serán las que los nombren. Ahora bien, la estadística se empeña en advertir que más bien la JAC actúa como un órgano de puro nombramiento y así, desde 2006 hasta 2013, de las casi 3.500 recomendaciones de candidatos, propuestas a la autoridad competente a efectos de su nombramiento ulterior, tan sólo no se tradujeron en cargos efectivos cinco.

Es imposible entender la naturaleza real de la JAC sin poner de relieve sus relaciones y cooperación permanente con el gobierno, concretamente con el Departamento de Asuntos constitucionales y de manera especial con el Ministro de Justicia. Las quince personas que integran la JAC desarrollan sus competencias a tiempo parcial, compatibilizando su actividad con la propia de su carrera profesional de origen. Serán retribuidas por dietas o compensaciones parciales.

\section{c) Los diversos procedimientos desarrollados para nombrar a los jueces.}

Es importante diferenciar dos ámbitos de trabajo en la JAC: el proceso ordinario de selección de candidatos en niveles judiciales hasta la High Court y, los procedimientos de selección de la denominada Senior judiciary que incluye: Lord Chief Justice, Senior President of Tribunals and Courts (SPTC), Heads of division y Jueces de la Court of Appeal. A estos dos procedimientos se suma la tarea desempeñada por la JAC en el nombramiento de los Jueces del Tribunal Supremo.

\section{Low level Judiciary y High Court incluidos.}

La mayoría de las recomendaciones de la JAC tienen lugar en todos estos niveles de puestos judiciales (low and medium level) incluidos los puestos de jueces a la High Court.

Primera fase: ¿Cómo se perfila el puesto vacante a cubrir?: Request for Selection (section 87 y 88 CRA de 2005).

El proceso comienza con la petición de un candidato a la JAC por parte de Lord Chancellor, exponiendo el puesto vacante a cubrir. Puede que tal requerimiento explicite más de una vacante a cubrir. Antes de exponer las características o exigencias propias del puesto, LC debe consultar a LCJ y en tales conversaciones/consultas deben fijarse la completa descripción del puesto a cubrir y las posibles cualificaciones específicas no regladas (adicionales o complementarias que ambos pudieran acordar pen- 
sando en las particulares necesidades del puesto). Es obvio que este "criterio adicional de selección” resulta incierto y problemático en las relaciones JAC, Ministro de Justicia y el departamento administrativo del Ministerio denominado Her Majesty Courts and Tribunals Service (HMCTS). Estos han dado prioridad, por ejemplo, a que el candidato pueda desarrollar de manera inminente las funciones del puesto para el que ha sido convocado y que cuente en su formación y habilidades profesionales con la mejor de las preparaciones posibles, de esta forma no será necesario un proceso previo de formación o adecuación mediante cursos o prácticas en el Judicial College (órgano encargado de la formación práctica de Jueces). El efecto que ello ha producido, durante los primeros años de funcionamiento de la JAC, ha sido reducir los candidatos potenciales y minimizar la posibilidad real de "diversidad" en los mismos.

Segunda fase: Configuración de la primera lista de candidatos que participan en los sucesivos trámites del denominado "selection day".

Una vez que la JAC conoce las necesidades del puesto o puestos a cubrir, los candidatos deben presentarse tras la convocatoria pública. Se abrirá un plazo para presentar la candidatura rellenando unos formularios previstos en la página web de la JAC y se tendrá que superar un "test" de preguntas cualificadas diseñado expresamente (especificidades, conocimientos y habilidades requeridas), por expertos en la materia y compañeros en activo en plazas judiciales similares. Sobre los mejores candidatos que hayan superado el test y cuenten con perfiles adecuados al puesto en cuestión, la JAC elaborará una lista, convocándolos a participar en la denominada jornada de "selection day". Esta jornada comprende una entrevista, una presentación por parte del candidato de su perfil y experiencia, una batería de preguntas con supuestos de hecho o casos posibles del puesto judicial a cubrir y un supuesto o role-playing lo más acorde con el día a día del puesto a cubrir.

Frente al candidato y para conocer como órgano supervisor de todas las referidas pruebas del selection day, se halla un panel de tres miembros. Dos de ellos son miembros laicos y, un tercero, será juez (preferiblemente del mismo ámbito y posición de la vacante). Los tres elaborarán un informe que será remitido a un miembro de la JAC (commissioner) seleccionado por el presidente de ésta para supervisar y dirigir todo el proceso, pero sin tomar parte directa ni en la elaboración de la lista, ni en la jornada selection day.

Varios aspectos han sido objeto de crítica: la excesiva influencia o peso del panelista de origen judicial, a pesar de ser los otros dos miembros ajenos a la profesión. Y la necesidad de recabar para los puestos de miembros laicos de las comisiones o paneles evaluadores perfiles variados y de niveles de formación adecuados, más altos de los que participaron en los primeros años de la JAC. 
Tercera fase: El proceso de consultas, statutory consultation ${ }^{65}$.

La siguiente fase del proceso y, una vez que ha tenido lugar el traslado del informe (elaborado por los tres miembros del panel al commissioner), es la consulta. La principal característica de esta consulta es que no es "vinculante" para el miembro de la JAC, pero si el candidato recomendado (por la JAC) no consigue una valoración positiva del sujeto consultado (LCJ para vacantes en High Court, otro juez con experiencia apropiada y relevante en la vacante para nombramientos low level Courts y para nombramientos de tribunales, Senior President Tribunals), deberá tal discrepancia ser fundamentada por la JAC en su informe (CRA, section 89).

La realidad de los hechos pone de relieve que en los nombramientos de los niveles medios y bajos de la judicatura no se producen discrepancias y sí en cambio surgen algunas a medida que los puestos a cubrir pertenecen a la Senior judiciary. Y suele ocurrir que el nombramiento no se produce por la autoridad competente, si el candidato recomendado por la JAC no coincide con la valoración positiva y conforme de la autoridad consultada. Una especie de veto encubierto que granjea la última palabra a los actores del viejo modelo.

De hecho, doctrina y miembros de la JAC han valorado de distintas maneras qué sentido y consecuencias se desprenden de las obligatorias consultas. Unos plantean que son "excesivas influencias", "intentos de manipulación” y otros, una información distinta y complementaria, difícil de conseguir con los procedimientos reglados/ formalistas pero que deviene utilísima por cuanto es capaz de evitar candidatos no apropiados, a la larga, para puestos importantes ${ }^{66}$.

Cuarta fase: La fase de recomendación del candidato por la JAC.

Llegados a este momento la JAC debe elevar su "recomendación” a la autoridad final de nombramiento competente según el puesto o vacante a cubrir. El mérito, el buen carácter y una clara apuesta, (de entre los candidatos posibles y en igualdad de méritos), por la diversidad serán los tres parámetros que considerar. El volumen y necesaria agilidad de las recomendaciones en aras de crear un procedimiento efectivo y eficiente hace que, en los dos encuentros al mes, aproximadamente, que mantiene la JAC se lleven a cabo alrededor de 75 recomendaciones, pero no todos los puestos deben ser objeto de comentarios o especial reflexiones. Lo normal es asumir los informes de los miembros de la JAC que a su vez dan por válidos las evaluaciones de los

${ }^{65}$ Es muy importante reflexionar sobre la "naturaleza" de la consulta, tan inserta en el "AND" británico. "... One of the mysteries of all this is that government departments still consult the judges as they draft legislation. For instance, Lord Woolfs Cambridge speech reveals that the judges were consulted by the Home Office as they drafted the Immigration Act. The problem for the judges was that the Home Office then ignored their advice..." WOOLF H., "Judicial Review, The tensions between the executive and the Judiciary”, Law Quarterly Review, 114, 1998, pp. 579.

${ }^{66}$ GEE G., MALLESON K., HAZELL R., and O'BRIEN P., op. cit. pp. 175 y ss. 
paneles. Y es para los casos que plantean alguna discrepancia o complicación, para los que la JAC dedica cierta parte y discusiones en sus reuniones.

Una vez que la recomendación ha sido hecha, la autoridad de nombramiento puede aceptarla, rechazarla o solicitar su reconsideración. Según la CRA solo cabe el rechazo, si se entiende que el candidato es inapropiado para el puesto, y la reconsideración, cuando no hay suficientes "evidencias" de que el candidato recomendado sea el mejor posicionado de acuerdo a la ponderación y valoración de los méritos. Todas las posibles autoridades de nombramientos deben "motivar" su rechazo o su decisión de reconsideración. En la práctica casi no se han producido.

\section{Senior Judiciary.}

Para la selección y nombramiento de los principales y más relevantes puestos de la judicatura inglesa (LCJ, SPT y Heads of division y jueces de la Court of Appeal) se articula un procedimiento separado. Esto ya en sí, no deja de ser indicativo.

Como para el resto de las vacantes, el punto de salida es también el esfuerzo de "descripción" de las habilidades y necesidades del puesto a cubrir. Tarea que no siempre refleja iguales pretensiones. Los jueces senior, consultados por LC, suelen coincidir en sus visiones conservadoras y clásicas de las necesidades y perfiles del puesto a cubrir, pero los cambios introducidos con motivo de la CRA 2005 y su reforma en 2013, han logrado introducir variables significativas en los “job descriptions" tan relevantes como la que directamente señalaba a LCJ en 2013 haciéndose hincapié en la capacidad de liderazgo y compromiso con la modernización de la justicia, la búsqueda incesante de eficiencia y eficacia y el firme compromiso con la diversidad.

Se crea un órgano ad hoc que hasta 2013 estaba compuesto por cuatro miembros y desde entonces se compone de cinco miembros, (dos elegidos por Lord Chief Justice). Preside LCJ quien tiene voto de calidad en caso necesario y además forman parte un juez senior, el presidente de la JAC que es un miembro laico y otro miembro de la JAC. Con la modificación a cinco miembros, el quinto será otro juez senior, pero siempre manteniéndose una mayoría laica.

Una de las notas propias de este procedimiento especial de la JAC es su gran opacidad y su escaso o casi inexistente formalismo. Si bien, desde 2011 aproximadamente, las cosas han ido cambiando y se da un mayor nivel de transparencia y formalización, en parte, fruto del "empecinamiento" de la realidad. El efecto producido por los procesos ordinarios de la JAC, creando una cultura de nombramientos más delimitada, formal, estable y rigurosa es indudable que se ha contagiado a todos los procesos que tienen lugar dentro de ella, retando con valentía las enraizadas inercias del viejo modelo ${ }^{67}$. El proceso ahora es más reglado, a pesar de su gran libertad de actuación. Las deliberaciones de los miembros del panel son secretas y ello es un gran

${ }^{67}$ ROSENBERG JOSHUA, "Senior judges are hanging up their wigs. Replacing them won't be cheap" The Guardian, 4 Abril 2016;

(C) UNED. Revista de Derecho Politico

N. ${ }^{\circ} 107$, enero-abril 2020, págs 71-109 
óbice para poder valorar el peso que juegan los seniors jueces y los miembros laicos en las negociaciones mantenidas valorando a los potenciales candidatos.

Asimismo, el papel jugado por Lord Chancellor (LC) en este tipo de nombramientos ha continuado muy activo y sigue estando presente como gran consultado no sólo en los paneles para nombrar a LCJ sino para todas las plazas "Senior". Sigue teniendo gran oportunidad de manifestar razonamientos o valoraciones de conveniencia o desacuerdo respecto de los candidatos.

En definitiva y respecto de las posiciones judiciales más relevantes o senior, los procedimientos siguen conservando "mucho" del viejo modelo y adoleciendo de legitimidad y diversidad. Por eso figuras relevantes como LADY HALE, actual presidenta del Tribunal Supremo del Reino Unido, han dicho que en el constitucionalismo actual los nombramientos de la senior judiciary son, en sentido amplio, un conjunto de actos políticos ${ }^{68}$.

3. La participación de la JAC en los nombramientos de los Jueces del Tribunal Supremo.

El procedimiento de selección de los Jueces del Tribunal Supremo es único y especial respecto de los vistos en párrafos anteriores. Este mecanismo se pone en marcha cuando se origina una vacante en el Tribunal Supremo de alguno de sus 12 miembros. Este órgano que es el vértice jerárquico del Poder Judicial del Reino Unido se crea en 2009 sustituyendo al antiguo Comité de apelaciones de la Cámara de los (CRA de 2005 Part 3, Schedule 23-60).

Se crea una comisión ad hoc compuesta de cinco miembros que está integrada por el Presidente de la JAC, el vicepresidente y otros tres miembros que representan, como commissioners, a los cuerpos públicos de nombramientos territoriales de Escocia e Irlanda del Norte, respectivamente: JABS (Judicial Appointment Board for Scotland 2002) y NIJAC (Northern Ireland Judicial Appointment Commission 2005). Es curioso que la CRA de 2005 tan sólo establezca que de estas tres últimas personas al menos una debe ser laica, pero en cambio no prefija la ponderación de representación territorial de los referidos órganos en cuanto a mayor presencia de Escocia o de Irlanda del norte.

La influencia judicial en la comisión explicada es un hecho y, si bien es cierto que el role jugado por Lord Chancellor ha quedado reducido a rechazar o solicitar una nueva reconsideración del candidato, no lo es menos que la comisión no estaría dispuesta a insistir en un nombramiento que no cuenta con la confianza del gobierno. A ello hay que añadir la consulta que suele trasladar la comisión, por prescripción normativa a Lord Chancellor, y a los primeros ministros de Escocia y Norte de Irlanda y a sus Secretarios de Estado y, por otro lado, a los jueces en activo del Tribunal

68 PATERSON A. y PATERSON C., "Guarding the Guardians? Towards an Independent, Accountable and Diverse Senior Judiciary”, London: Centre-Forum, 2012, pág. 36 y ss. 
Supremo. Once opiniones de la máxima relevancia, por cuanto conocedores de primera mano de la realidad y problemas de este órgano y que serían muy difícilmente rebatibles por el resto de los miembros de la comisión.

¿Quién guarda al guardián? ¿Cómo se nombran o seleccionan los commissioners que integran la JAC? Quizá podríamos, para entender mejor el modelo británico referirnos a la máxima de "no poner todos los huevos en la misma canasta..." Porque si alguna característica es unánimemente compartida por los expertos y académicos que han analizado y estudiado este órgano es su gran complejidad en la selección de sus 15 miembros regulada en el Statutory Instrument $n^{\circ}$ 2191, Judicial Appointments Commission Regulations de 2013. La JAC está compuesta de 15 miembros (commissioners) incluido el Chairman, pero no todos tienen la misma procedencia. Siete pertenecen al ámbito Judicial, seis son miembros "laicos" o legos en Derecho y, por último, dos miembros ejercientes de la profesión legal (legal practitioners) que podrán ser Barrister, Solicitor o Fellow (Chartered Institute of Legal Executives, algo así como un abogado en ejercicio).

La selección de los miembros de la JAC se hace mediante un proceso abierto competitivo (concurso de méritos en combinación con otras pruebas que forman parte del proceso para postular al puesto) ante el Ministerio de Justicia, de manera expresa ante Lord Chancellor (Ministry) a excepción de tres de los miembros con perfil judicial (los seniors de entre los siete) que serán nombrados por el Consejo de los Jueces (Judges' Council).

Se crean paneles de cuatro expertos que serán elegidos por Lord Chancellor, Lord Chief of Justice (LCJ) y Senior President of the Tribunal respetando una gran heterogeneidad de composición en cuanto a perfiles y especialidades (regulations 13 y 14 Statutory Instrument 2013, n $\mathrm{n}^{\circ}$ 2191) y que elegirán todos los demás miembros de la JAC que no caen bajo la elección directa del Consejo Judicial.

\section{d) Valoración del modelo inglés ${ }^{69}$.}

Una Judicatura muy prestigiosa a lo largo de los años, prácticamente sin cuestionamientos. ¿Por qué abordaría tan profunda reforma? Desde aquellos jueces creadores del common law, independientes del poder regio que Sir Edward Coke a principios del siglo XVII dignificó, hasta estos jueces "enemigos del pueblo ${ }^{70 "}$ que la prensa inglesa burdamente insultó con motivo del caso Miller en 2016 fallado por el Tribunal Supremo; ¿qué ha cambiado?

69 "...White and male judiciary "from another planet", says Lady Hale" en The Guardian, 1st January 2019.

70 The Guardian, $4^{\text {th }}$ November 2016, "British newspapers react to Brexit's ruling: Enemies of the people".

(C) UNED. Revista de Derecho Político

101

N. ${ }^{\circ} 107$, enero-abril 2020, págs 71-109 
La separación entre la recomendación y el nombramiento.

Es conveniente, de acuerdo a la reforma constitucional, separar recomendación de candidatos y nombramiento de estos. Aquella tarea es llevada a cabo por la JAC, y esta, por las autoridades de nombramiento. Los miembros de la JAC desarrollan una labor de filtro "en tiempo real" y esto es importante respecto de los potenciales candidatos a ocupar el puesto. La JAC tiene como objetivos a cubrir: seleccionar candidatos con procedimientos basados sólo en el "mérito", recomendar candidatos que tengan "buen carácter" y orientar sus procedimientos de selección y análisis de los candidatos desde un firme compromiso con la "diversidad". No estamos ante un proceso que analiza y valora un curriculum cerrado y unos méritos documentados que se exponen y defienden, los procesos de la JAC combinan estrategias activas que pretenden evaluar los candidatos en tiempo real con toda una serie de pruebas y actividades enfocadas a ello (short listing, selection day, role play...)

La diversidad ha sido siempre la asignatura pendiente, no sólo por su desprecio durante muchos años de historia británica de nombramientos judiciales, sino por su deficiente comprensión e implementación en sucesivos años de laborismo y gobiernos torys. Los denominados BAME (Black people, Asian and Minority ethnics) o colectivos minoritarios de la sociedad británica han estado relegados a planos muy secundarios del mundo judicial. Y así, por ejemplo, hasta 2004 no llega a la High Court ninguna jueza mujer y de color. Será Linda Dobbs quien lo haga por primera vez. La diversidad significa a medio y largo plazo una nueva visión y aires frescos en la aplicación de las normas, en esa búsqueda incesante de la "justicia". No siempre hombres, no siempre blancos, no siempre modelo de educación "Oxbridge", no siempre "Barrister" como perfiles más cotizados para los puestos de la Senior judiciary.

La "legitimidad" de la justicia requiere no sólo de buenos procedimientos para nombrar los jueces, sino un claro compromiso con la renovación de quiénes podrían ser los mejores candidatos para esos puestos. La independencia judicial requiere también de amplitud de perfiles y sensibilidades en sus jueces que reflejen la verdadera heterogeneidad de la sociedad, última destinataria de los fallos judiciales.

La claridad, visibilidad y tangibilidad de relación entre el ejecutivo (Lord Chancellor y Constitutional affair Department) y la JAC.

El modelo actual es consciente del profundo peso que tiene la "política" en los procesos de nombramientos de jueces. Esto no es nuevo y tampoco exclusivo de este modelo contemporáneo. Nombrar a los titulares del poder judicial es elegir a quienes deben asumir los poderes y responsabilidades de la iuris dictio. El peso de la ley en el Estado de Derecho se administra por los que ya en las revoluciones liberales burguesas fueron "boca de la ley". 
Pero ser consciente de tal presencia, empecinada y persistente presencia, de la política en los procesos de nombramientos de jueces no es más que un primer paso y como tal no es suficiente. Después habría que diseñar nuevos estadios o fases. ¿Cómo y hasta cuánto permitir que la lógica política y sus objetivos inunden los procesos de selección de la judicatura? Esconder la interacción de una y otros, puede ser una actitud, máxime cuando aquélla pretende, sin límites, dominar éstos. Reglamentarla de manera clara, sencilla y transparente y sin "tapujos", puede ser otra. La idea que nos propone la JAC adopta como actitud, tras el "estado de aceptación y consciencia”, la visibilidad, claridad y tangibilidad de los efectos de la política en los appointments procedures.

Visibilidad, porque las normas que regulan la composición y funciones de la JAC (CRA de 2005 y CCA de 2013 y JAC Regulations 2013) describen un procedimiento claro de recomendaciones, por un lado, y autoridades de nombramiento judicial, por otro. Autoridades que son parte activa de la política (Ministry of Justice) y estrecha colaboración con el Departamento de Asuntos constitucionales, dentro del ejecutivo (Department for constitutional Affairs DCA). En realidad, la mayoría del personal al servicio de los commissioner trabaja apoyado y en cooperación con el DCA.

Claridad, en cuanto que Lord Chancellor será responsable (accountable) ante el Parlamento, del desarrollo y de las actividades que son desempeñadas por la JAC. Los objetivos y retos que asumirá la JAC en su periodo anual de ejercicio, así como las directrices de su Staff, de sus commissioners, su Presidente y Jefe ejecutivo (Chair y Chief of executive) son aprobados por Lord Chancellor. Claridad también puesta de relieve en el envío de los puestos vacantes a cubrir, (su localización y las exigencias, requerimientos o perfiles oportunos de tales plazas, especificados al máximo) en el ánimo de presentar a Lord Chancellor un único nombre. Así se limita in extenso el derecho de "rechazo" o "nueva reconsideración" de Lord Chancellor sobre el candidato propuesto. Un clarísimo ejemplo de nuevo diseño en la relación política-nombramiento judicial.

Tangibilidad de los efectos de la política sobre los procesos de recomendación-nombramiento tal como se desprende de la "jerarquización" de las autoridades de nombramiento y de los puestos o vacantes judiciales a cubrir. No será igual nombrar a un Juez de la High Court, que a un Magistrado de distrito. Y por eso, tal como hemos descrito el proceso los reportes de las recomendaciones, dependiendo del puesto a cubrir, será destinado a autoridades de nombramiento distintas. Proximidad clara y palpable de la fuerza de lo "político" y "la política", en los casos de rechazo o petición de reconsideración, que consiguen finalmente evitar el nombramiento.

Es necesario medir, en el ánimo de aprovechar y limitar pautadamente y controladamente, la presencia de la política en los nombramientos judiciales. Vendría a ser, tanto por la forma como por el fondo, el equivalente a una "voladura controlada". Esta es a nuestro juicio la clave: participar activamente en el diseño y límites de la relación política-nombramientos.

(C) UNED. Revista de Derecho Politico

N. ${ }^{\circ}$ 107, enero-abril 2020, págs 71-109 
El difícil y conveniente equilibrio en los múltiples perfiles presentes en los miembros de la JAC.

Se trata de concitar, equilibradamente, Jueces, juristas y personas de fuera del mundo judicial. Se establece, prescriptivamente, que la presidencia de la JAC debe ser ejercitada por un perfil laico en derecho y al mismo tiempo se reconoce la importancia de la presencia de un "juez" en los paneles de selección, subrayando la no reemplazable tarea que debe desarrollar éste.

La representación de la pluralidad social, los necesarios distintos perfiles, la insustituible formación profesional técnica, la experiencia y "veteranía" o madurez de los Jueces senior, son imprescindibles. ${ }^{71}$ Pero también el "aire fresco" que representan los perfiles laicos.

El efecto del "rechazo" o sugerencia de "nueva reconsideración” por parte de Lord Chancellor.

Cuando la recomendación que hace la JAC llega al Ministro de Justicia en los procesos normales sustanciados ante aquella, se pueden producir tres opciones. Primero, que se acepte la recomendación y se proceda al nombramiento poniendo este a disposición de su Majestad la Reina; segundo, que se rechace el candidato recomendado y, tercero, que se solicite a la JAC una "reconsideración” del candidato en concreto. Estos dos últimos supuestos se originan, bien porque se entiende que no son los más apropiados para el puesto o vacante a cubrir, bien porque se considera que no hay suficientes evidencias que avalen al candidato para el puesto. Todo ello se aclara ante la JAC y se le pide que lo razone o justifique de manera escrita. La JAC puede, por tanto, plantear un nuevo candidato (en caso de rechazo del primero) o en caso de reconsideración, plantear otra vez el mismo, dotándole de más evidencias que lo apoyen, o intentar de nuevo el candidato primeramente propuesto. También aquí LC cuenta con las mismas opciones de rechazo/reconsideración por lo que podría darse una tercera ronda de recomendaciones e intervención de la JAC e incluso un tercer y nuevo candidato propuesto. Pero tras esta hipotética tercera ronda, LC tendría que bien aceptar alguno de los "no rechazados" anteriormente o el propuesto en la tercera ronda. Es evidente que el poder de "rechazo/reconsideración" se ha visto recortado.

La excesiva complejidad burocrática de los procesos.

La práctica ha puesto de relieve que los procesos son demasiado largos y que, a pesar del incremento de presupuesto, se requiere mucho personal gestionando los

${ }^{71}$ GRAHAM GEE, Judging the JAC. How much judicial influence over judicial appointments is too much? Debating Judicial Appointment Commission, Routledge 2018, capítulo 8; 
pasos o fases del mismo. Los primeros años de vida de la JAC llevaron a todos los sectores implicados a criticar la excesiva "burocratización" de un procedimiento lento y complejo ${ }^{72}$. Si bien es cierto que la situación ahora ha mejorado, suavizándose las relaciones entre el gobierno, y los sectores más críticos de la Judicatura.

\section{CONCLUSIONES: A MODO DE SINERGIAS, PREOCUPACIONES Y REFLEXIONES TRAS LA COMPARATIVA.}

Hablar del Consejo General del Poder Judicial es pensar en gobierno de Jueces y Magistrados, pero hablar de estos últimos es pensar en el valor de la Justicia, como fin último a construir día a día, fallo a fallo, proceso a proceso, justiciable a justiciable. Disfrutaremos un Poder Judicial “justo” si es, entre otras necesidades, independiente. Reino Unido y España dos modelos distintos, un mínimo común denominador y una reflexión de fondo divergente. El método comparado que hemos utilizado ha huido de la seducción del "mito" y del estéril consuelo del "placebo". No es mejor todo lo que no se tiene. El proceso (cada proceso) es fruto del contexto, del modelo judicial y del momento. Queremos buenos jueces, para ello necesitamos diseñar mejores procesos de selección.

1) La apariencia de imparcialidad e independencia es vital, tanto como la esencia y realidad de la misma. No se confía en una justicia que no tiene apariencia de independencia e imparcialidad.

2) El gobierno de Jueces y magistrados es un órgano que nombra a éstos, les inspecciona y sanciona. Les permite promocionar o ser elegidos para diversos puestos, dentro de la función judicial. El artículo 122 de la CE se refiere al Consejo en esos precisos términos: nombramientos, ascensos, inspección y régimen disciplinario. Todo este poder ejercitado por el Consejo tiene, desde luego, un importante componente político. Esto debe asumirse desde el principio, negarlo es un error.

3) El elemento "política" no puede obviarse en los procedimientos de selección de jueces. Ello solo puede significar que se "esconde", se "ignora" o se "niega". La Comisión de Venecia declara: "The mere existence of a high judicial council cannot automatically exclude political considerations in the appointment process..." 73

4) Los procedimientos deben ser claros y transparentes. Deben desarrollarse "equilibradamente", esto es, apostando por el mérito, la capacidad, la pluralidad social, la representatividad del mundo de la Judicatura y la igualdad de género.

${ }^{72}$ GRAHAM GEE y ERIKA RACKLEY, op. cít., Capítulo 1: “Introduction. Diversity and the JAC's first ten years", págs. 21 y ss.

73 Op cit, pág. 5;

(C) UNED. Revista de Derecho Político

N.o 107 , enero-abril 2020, págs 71-109 
5) ¿Concentrar en un mismo órgano: nombramiento, ascenso, inspección y régimen disciplinario, es independiente? ¿Permite una apropiada y suficiente rendición de cuentas? Si los nombramientos discrecionales de la Alta Judicatura, constituyen actos con un claro componente político, con carácter discrecional, no basados en el argumento de "cargos de confianza", no arbitrarios, no carentes de motivación, no discriminatorios pero sí POLÍTICOS, un buen diseño de un proceso de nombramiento de jueces debe apostar por: a) Convocatoria pública, b) órgano de propuesta distinto a órgano de consultas y distinto a órgano de nombramiento, c) procedimiento claro, sencillo, transparente, eficaz, eficiente, de naturaleza "predominantemente judicial" y auditable, no sólo judicialmente, sino también al estilo británico del concepto "accountability".

6) Los jueces deben ser representativos de toda la sociedad, y aún más si son "altos cargos de la judicatura". Deben estar legitimados por su mérito, por su especialización, por su experiencia, buen carácter y buen comportamiento... Pero también deben estar legitimados por su personal concepción política de la Justicia, sobre todo para ocupar ciertos cargos o puestos dentro de la Judicatura que no sólo requieren de "magníficos expertos en derecho o brillantes conocedores de la jurisprudencia nacional e internacional", sino de otras habilidades y competencias que son las mismas que han justificado que no son cargos de nombramientos reglados, sino que son cargos de naturaleza discrecional.

Esto es lo que una Justicia independiente debe someter a la "luz y taquígrafos". Esta parte del nombramiento de los jueces, los discrecionales, deben hacerse de manera pública y transparente, abundando en las exigencias de la plaza a cubrir (Jobs descriptions), cambiando las votaciones secretas por votaciones públicas en el Pleno del Consejo, recuperando el quórum de constitución (ahora sólo 10) o las mayorías reforzadas para adoptar acuerdos y huyendo de reformas de la LOPJ que justo se orientan en la línea contraria (art. 564 de la ley 4/2013). En la línea equivocada de más competencias a la Comisión permanente, en la línea de eliminar el recurso en alzada ante el Pleno del Consejo, en la línea de un Presidente con mayor peso real y efectivo, en la línea de una posible "renovación parcial” de sólo 10 vocales. Esto claramente no es la línea de la "rendición de cuentas" de la "accountability".

7) Principios como "administración de la justicia en nombre el pueblo...", "los jueces fiel reflejo de la sociedad que conocen bien", son descuidados y convertidos en papel mojado, si los procedimientos de nombramiento no presentan cifras equiparables de hombres y mujeres en todos los niveles jerárquicos de la carrera judicial, si no existen distintas "sensibilidades" y "políticas de la justicia" en los jueces nombrados. Eso en el modelo inglés se denomina BAME, Black people, and African minorities ethnics, que no sólo premian el pack "Oxbridge", Juristas que proceden de Oxford y 
Cambridge, no sólo prestigiosos Barrister sino también modestos Solicitors. Y si lo aterrizamos en el modelo español, estamos hablando de huir de la "mayoría progresista o conservadora" de los vocales del Consejo, impedir que si el porcentaje mayoritario de acceso a la carrera judicial, rondando el $75 \%$, son mujeres no se reduzca al $13,9 \%$ en el Tribunal Supremo, significa que no militar en una de las Asociaciones profesionales de la Judicatura o la magistratura no debe ser algo imprescindible en la promoción profesional de nuestros jueces.

8) El método comparado en nuestro tema de nombramientos judiciales ofrece una visión de dos modelos España y Reino Unido profundamente distintos, pero con preocupaciones y retos muy similares: civil law frente a common law; con una Constitución escrita frente a un sistema de unwritten constitution. Un país abordando el reto del Brexit, en medio de unos primeros años de vida de su "Devolution process", con una joven Human Right Act (1988) y una Judicatura sorprendida y descolocada por la creación de la JAC y del nuevo Tribunal Supremo (2009); Y en paralelo España, con un órgano de Gobierno de Jueces y Magistrados de naturaleza constitucional (art.122CE), en constante estado de "inquietud" por su búsqueda incesante de acomodo y legitimidad, que atesora en sus competencias: nombramientos, disciplina, promoción y control. Con diversas Asociaciones de la Judicatura y Magistratura tratando de colorear la política de la independencia judicial, tratando de digerir recientes reformas y debates parlamentarios de "desreformas".

9) Las soluciones de España y Reino Unido ponen de relieve una común preocupación: la independencia Judicial "pasa por" y se "construye" también, con un sistema de nombramiento de jueces justo, de calidad, libre y legítimo.

10) La gran divergencia entre los dos modelos descansa en cómo se entiende e incorpora el elemento "político" en los procesos de nombramientos de jueces. Ese ingrediente político surge en medio de la necesaria "discrecionalidad" de algunos nombramientos. Tiene que sumar y no restar nunca independencia judicial. De ahí que, por ejemplo, el Reglamento de 2010 que regula los nombramientos discrecionales refleje en los perfiles para plazas jurisdiccionales-gubernativas como requisito, "el programa de actuación para el desempeño de la plaza solicitada” (art. 7).

Si en España se huye del ingrediente político porque se considera negativo y lesionador de la tan buscada "independencia judicial". Cualquier reforma nace bajo el paraguas de la regeneración del Poder Judicial y la lucha frente a la politización de la justicia. La política de la Independencia Judicial no es, en absoluto, la politización de la justicia. En el Reino Unido desde 2005, lo “político” se acepta porque está identificado, por ejemplo, en las consultas que se hace antes de ciertos nombramientos a la Senior Judiciary, en la selección de las autoridades de nombramientos, en la capacidad de rechazo o nueva consideración de un candidato en manos de Lord Chancellor 
(Ministro de Justicia), etc. Toda la Constitutional Reform Act responde a la lucha e incesante búsqueda de la política de la independencia judicial. Sin duda será una conquista "política" el logro de la ansiada independencia judicial.

"...Newspapers have repeatedly said that there is a state of tension between the judges and the Home Secretary. The implication is that this is an undesirable state of affairs. That is a misconception. It is when there is a state of perfect harmony between the judges and the executive that the citizens need to worry..." "74

Title:

How are appointed the Judges and Magistrates? A wider view over the Spanish and British models.

\title{
Summary: \\ I.- INTRODUCTION II.- THE RULED AND DISCRETIONARY PROCEDURES TO APPOINT JUDGES IN SPAIN a) The competences of the General Council of the Judicial power over appointments; b) How has the Jurisprudence evolved referring to "discretionary appointments". III.- THE REAL MEANING OF THE SELECTION PROCEDURES FOR JUDICIAL INDEPENDENCE. IV.-THE BRITHIS APPOINT- MENTS OF THE JUDICIARY AFTER THE CONSTITUTIONAL RE- FORM ACT IN 2005.V.- CONCLUSION: A SORT OF SYNERGIES, CONCERNS AND REFLECTIONS AFTER HAVE BEEN MADE THE COMPASION BETWEEN SPANISH AND BRITHISH SYSTEMS.
}

\begin{abstract}
:
When we speak about Judicial independence is very crucial to distinguish different parameter in order to understand properly, what judicial independence is? One of the most important issue is the procedures to appoint Judges and Magistrates. That issue is relevant in order to reach independent, legitimate, representative and fair Judges. Some concerns should
\end{abstract}

${ }^{74}$ Lord Steyn, Administrative law Bar Association 1996, cited by STEPHEN SEDLEY, Lions under the throne. Essays on the History of Public Law, Cambridge University Press, pp. 2; La idea de estas líneas sería que mientras los periódicos se hacen eco repetidamente de la preocupación que significa la tensión permanente entre los jueces y el ejecutivo, estas tensiones e implicaciones entre uno y otro no son nada bueno. Tal lógica es "no entender" la verdadera realidad de las cosas porque es cuándo existe "armonía y buen entendimiento" entre Jueces y poder ejecutivo cuando deberíamos preocuparnos y sentir la amenaza de la independencia judicial. 
be taken into account by the selection procedures: the merit, capability, specialization and firm commitment with the diversity. It's completely necessary to have a Judiciary which be representative with our real society.

\section{Resumen:}

Cuando hablamos de independencia judicial es importante desgranar los múltiples parámetros que son decisivos para su análisis. Uno de los más importantes es la forma en que se nombran los Jueces y Magistrados en un determinado modelo. Los procedimientos son decisivos para poder conseguir jueces justos, legítimos, representativos e independientes. Varios aspectos deben considerarse y respetarse en los procedimientos de selección de la judicatura: el mérito y la capacidad, la especialización y el firme compromiso con la diversidad. Y todo ello en el ánimo de lograr una judicatura representativa de la sociedad real.

Key words:

Judicial independence, Accountability, the politics of the Judiciary, procedures to appoint Judges, the principle of merit, legitimacy of the judiciary. Diversity.

\section{Palabras clave:}

Independencia Judicial, Responsabilidad, la política de la Independencia judicial, procesos de nombramientos de jueces, mérito, capacidad, legitimidad, diversidad. 